\title{
Meat and Dairy Consumption Drivers: \\ Exploring the Values and Ethics that \\ Define People's Attitudes in Wellington
}

Mariam Fahed Alzaabi

Thesis

Environmental Studies 593

2020

A 90-point thesis submitted to the Victoria University of Wellington, as partial fulfilment for the degree of Master of Environmental Studies

School of Geography, Environment and Earth Sciences

Victoria University of Wellington

August 2020 


\begin{abstract}
Over the past few decades, rising meat and dairy consumption has had increased environmental implications, ranging from soaring greenhouse gas emissions to river pollution in Aotearoa New Zealand. Recent studies suggest the importance of altering meat and dairy consumption attitudes to reduce environmental damage, and researching people's meat and dairy consumption drivers plays a crucial role in understanding behavioural change and encouraging alteration in meat and dairy consumption attitudes. Changing people's attitudes around meat and dairy consumption is vital to reducing environmental degradation. Furthermore, moving towards a less meat- and dairy-intensive diet can be beneficial not only for the environment but also to personal values and ethics.

This research aims to understand how some people in New Zealand society perceive their attitudes around meat and dairy consumption and its implications for the environment, as well as contribute to behavioural change. Qualitative research methodology was applied to understand four drivers that define people's attitudes towards meat and dairy consumption. These drivers stem from domain-specific value- and ethics-based attitudes. Face-to-face interviews were conducted to collect in-depth data on how individuals perceive the environmental implications of meat and dairy consumption from faith-based, health-based, environmental ethics and animal welfare viewpoints. Implications of these drivers and their combinations to inform behavioural change are discussed, as well as how findings from this research can inform behavioural change. Further, this research aims to contribute to future educational campaigns that encourage sustainable choices for individuals whose values and ethics drive their attitudes around meat and dairy consumption.
\end{abstract}

Key words: values, ethics, attitudes, meat consumption, environmental implications, theory of planned behaviour. 


\section{Acknowledgements}

Being an artist and a pianist most of my life, the academic life was never something I thought I would ever embark on. But I was wrong, and writing this thesis was the best decision I have ever made so far.

I would like to thank my supervisor Paul Blaschke whom I was fortunate to have as a great mentor. Without his wise words and kindness, my journey would have been much harder. I also would like to thank my co-supervisor Marcela Palomino-Schalscha who gave me advice on how to approach my thesis. Thank you to Wokje Abrahamse, whose research gave me the courage to pursue my master's in this particular field, and for her kind gesture to guide me through the initial stages of my thesis writing journey.

I'm very grateful to all my interview participants, who gave their valuable time as part of my research.

Thank you to my mother; without her prayers I wouldn't have made it this far. To my brother, sisters and best friends who have been with me through the ups and downs that led me to this moment. Finally, thank you to Guy Randall, who has been with me during the worst and the best moments of this journey, advising and protecting me from making massive mistakes since the beginning.

Thank you! 


\section{Contents}

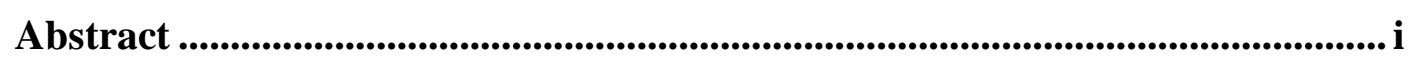

Acknowledgements ..................................................................................................ii

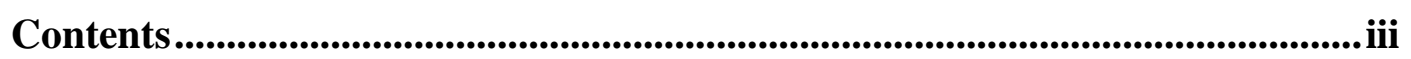

List of Figures ................................................................................................. v

List of Tables............................................................................................................. vi

List of Appendices ........................................................................................................... vii

Chapter 1: Introduction .................................................................................................... 1

1.1 Meat and dairy consumption, society and attitudes......................................... 2

1.2 Research motivation and significance …………………................................. 3

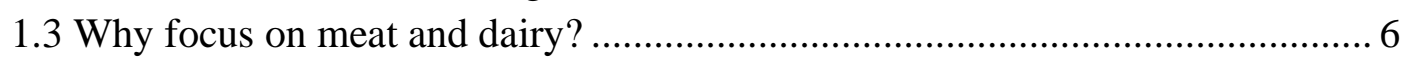

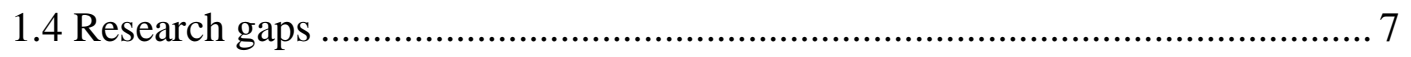

1.5 Research aims and questions ................................................................. 8

Chapter 2: Literature Review ................................................................................ 10

2.1 Background ........................................................................................... 10

2.2 Key terms associated with values and ethics .................................................. 11

2.3 Domain-specific value drivers .................................................................. 15

2.3.1 Faith-based attitudes towards meat and dairy consumption ....................... 17

2.3.2 Health-based attitudes towards meat and dairy consumption ...................... 20

2.4 Ethics-based drivers................................................................................. 22

2.4.1 Environmental ethics attitudes towards meat and dairy consumption....... 23

2.4.2 Animal welfare attitudes towards meat and dairy consumption ................. 30

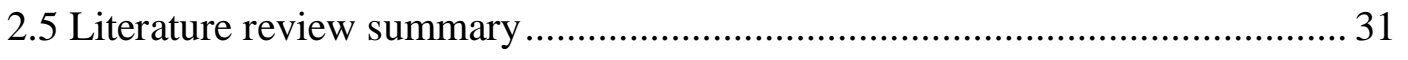

Chapter 3: Methodology ................................................................................................ 33

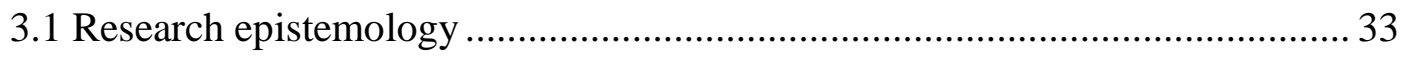

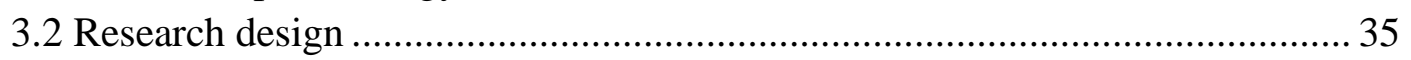

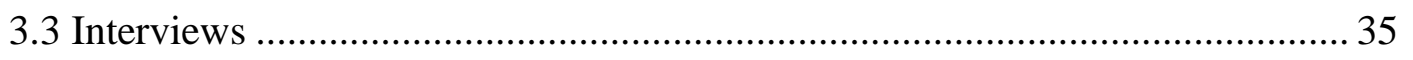

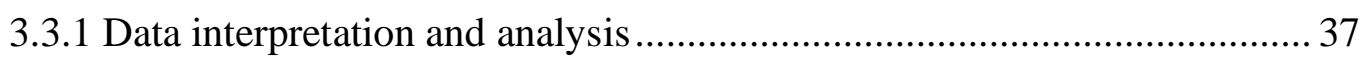

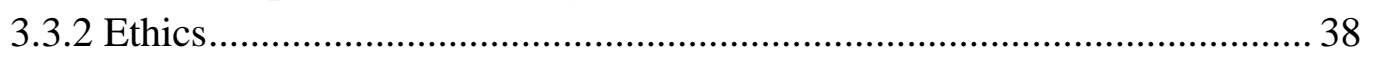

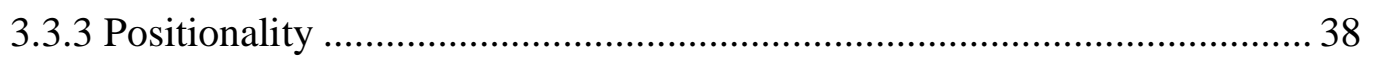

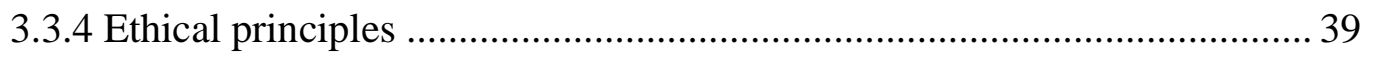

3.4 Methodology summary ........................................................................... 40

Chapter 4: Results-Perspectives on meat and dairy consumption.................. 41

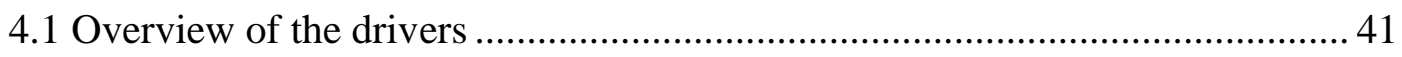

4.2 Interview findings for domain-specific value drivers........................................ 43

4.2.1 Faith-based values influencing people's attitudes ..................................... 43

4.2.2 Health-based values influencing people's attitudes.................................... 46 


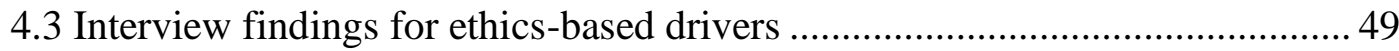

4.3.1 Environmental ethics influencing people's attitudes ............................. 49

4.3.2 Animal welfare influencing people's attitudes ........................................5 52

4.4 Crossovers between values and ethics views ................................................. 54

4.4.1 Health-based values — environmental ethics crossover ........................... 55

4.4.2 Faith based values — environmental ethics crossover .............................. 56

4.4.3 Faith-based values — animal welfare crossover ...................................... 57

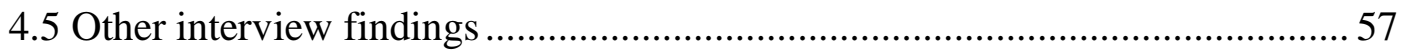

4.5.1 Cultural drivers on influencing people's attitudes ....................................57

4.5.2 Relationship drivers on influencing people's attitudes ...........................5 59

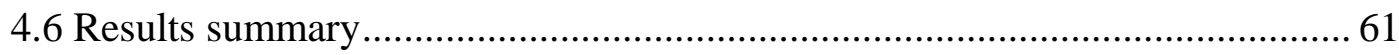

Chapter 5: Discussion — exploring attitudes................................................................6 63

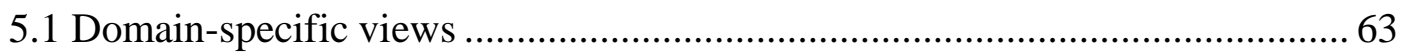

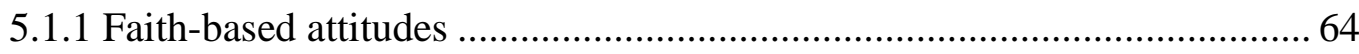

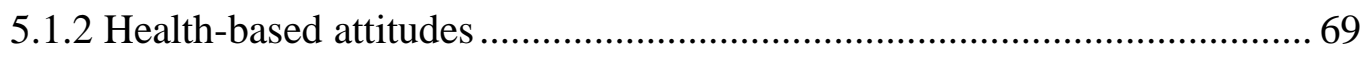

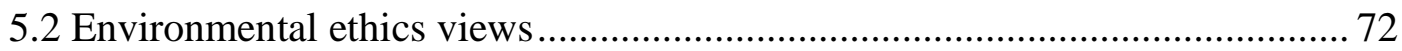

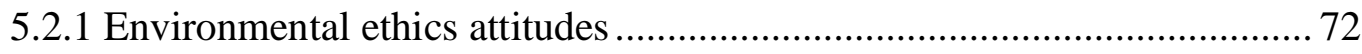

5.2.2 Animal welfare.......................................................................... 73

5.3 Emerging drivers influencing meat and dairy consumption attitudes ............. 75

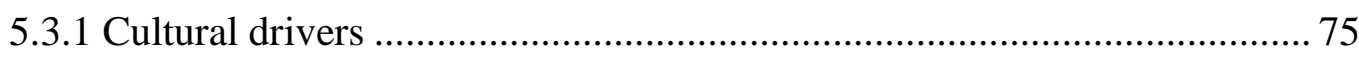

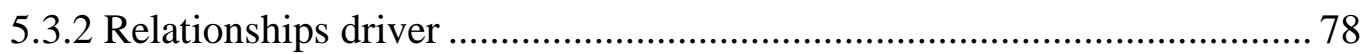

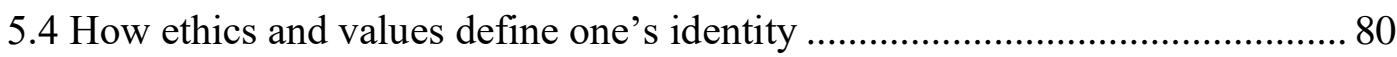

5.5 Mitigation of environmental implications through consumption attitudes change 82

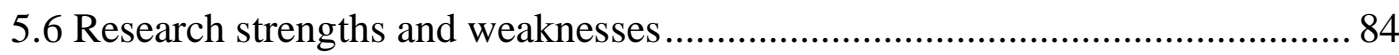

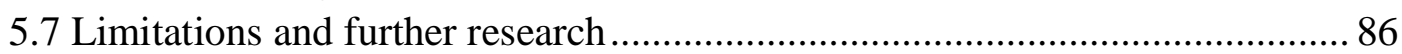

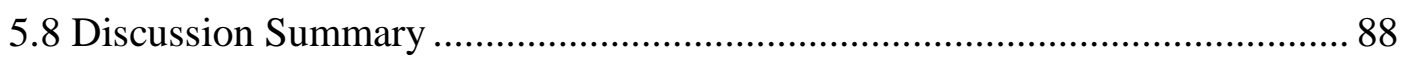

Chapter 6: Conclusion-Where to from here? ..................................................8 89

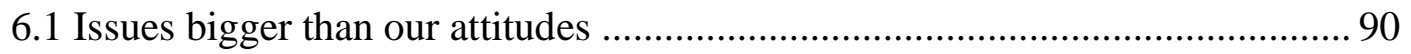

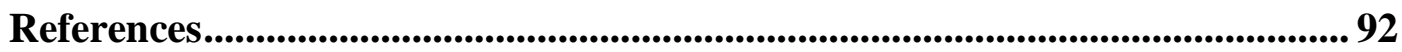

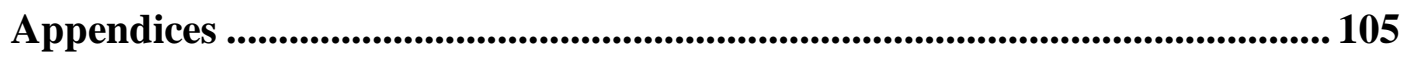




\section{List of Figures}

Figure 1.1. The researcher's conceptual framework ............................................ 5

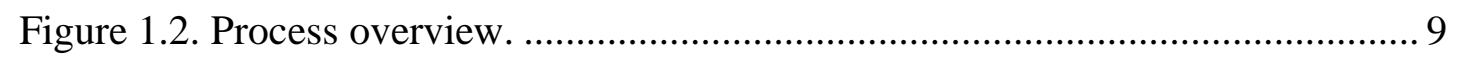

Figure 2.1. The relationship between values, ethics and attitudes. .......................... 12 


\section{List of Tables}

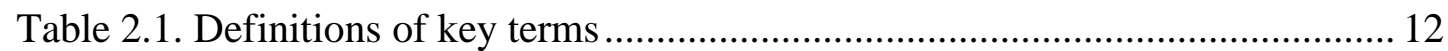

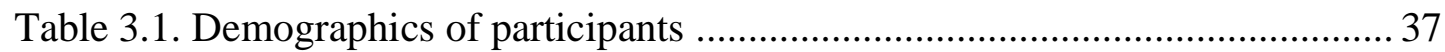




\section{List of Appendices}

Appendix A: Information sheet for participants

105

Appendix B: Consent to interview

108

Appendix C: Questions list for participants

110

Appendix D: Email to participants....

113 


\section{Chapter 1: Introduction}

\section{For eating is that indispensable vital activity closest to the mindlessly natural, yet it is also influenced by the emergence of mind and culture.}

Leon Kass, The Hungry Soul (1999)

In his philosophical book The Hungry Soul: Eating and the Perfecting of our Nature, Kass (1999) explored eating as a guide to morality and everyday life. He emphasised the importance of appreciating the necessities of everyday life, by understanding the wisdom of feeding not only the body, but also the soul. Food is not solely about survival; consumption is also driven by our beliefs, values and ethics.

Over time, there have been many issues raised about what we eat and how we eat our food. Currently, matters related to the effect of meat and dairy production on the environment and ecosystems are more prominent than ever (Willet et al., 2019). The global population has been on the rise since the Industrial Revolution, and with this increase came the increase in the production of livestock. The United Nation's medium-variant world population projection forecasts that the total population could grow to around 8.5 billion in 2030, 9.7 billion in 2050, and 10.9 billion in 2100 (UN, 2019). While the increase in animal-based consumption is linked to the rise of the human population, the basis on which people select their meat and dairy consumption is complex: personal preference, availability and societal capacity play a role in determining those choices.

This introductory chapter aims to give a background on the topic of the values and ethics that define people's attitudes around meat and dairy consumption, introduce the research motivation for this thesis and highlight its significance. It justifies why the consumption of meat 
and dairy was chosen over other types of food for this study and explains the research gap to be filled and the research questions to be answered.

\subsection{Meat and dairy consumption, society and attitudes}

Dowd and Burke (2013) noted that hunger is not the sole driver of the food we choose to eat. Nutritional, religious, ethical, psychological, economic, and food security determinants play a significant role as well. An individual's perception of these drivers, as well as the nature of different foods, determine that individual's overall pattern of food consumption. To illustrate, Pilgrim (1957) proposed one of the earliest models1 of determinants of food consumption behaviour. In his model, food consumption is dependent on perception. To Pilgrim (1957), food perception consists of three factors: 1) physiological effects of the food, 2) perception of sensory attributes, and 3) influences from the environment. From this, Pilgrim (1957) determines that these factors interact in influencing food consumption. As for environmental concerns, a study conducted by the University of Otago on New Zealand consumer lifestyle changes showed that 28 per cent of the population displayed concern with environmental issues related to their consumption attitudes. The importance of sustainability was the most significant change identified in the study (Watkins et al., 2015).

Personal values and ethics have been playing a role in shaping people's attitudes behind their food consumption, particularly concerning meat and dairy consumption drivers. Increased meat and dairy consumption has seen increase in supply. Research indicates that meat production profoundly affects the environment due to the enormous amounts of resources required, including land, water, material and energy (Elferink et al., 2008). The EAT-Lancet report (Willett et al., 2019) indicated that food production is among the most significant driver

1 Models: A model helps to systemise the specific type of work and serves as a guide for establishing testable hypotheses. 
of global environmental change; the report also identified behavioural changes as one of several approaches that can reduce the environmental effects of food production. (Willett et al., 2019).

Statistics show that the numbers of those who are on meat- or dairy-free diets is small compared to those who consume meat and dairy (Ritchie and Roser, 2017). But it is valuable to explore the motivations of those people who do choose a meat- or dairy free diet, because of the environmental implications of their choices. These people include vegetarians, vegans 2 and 'flexitarians' 3 . This thesis examines motivations and drivers of the food choices of such people as well as people who choose to eat all types of food. The research looks at four broad drivers: human health, faith-related values, environmental ethics and animal welfare. These drivers will be discussed in Chapter 2 .

While behavioural changes can be one of several approaches that can mitigate environmental damage from food production, the process of effecting behavioural change can be complicated; however, it is not unachievable.

\subsection{Research motivation and significance}

Evidence from the EAT-Lancet report (Willett 2019) indicated that food production is among the most significant drivers of global environmental change, by contributing to climate change, biodiversity loss, freshwater use, interference with the global nitrogen and phosphorus cycles and land-system change. Moreover, the report identified three approaches that can reduce the environmental effects of food production, and one of them is behavioural changes alongside technological and management-related changes in food production (Willett et al., 2019).

\footnotetext{
2 Vegan: coined by Donald Watson in 1944, the term vegan or veganism is the practice of abstaining from the use of animal products, especially in diet.
}

3 Flexitarian: an individual who primarily eats a vegetarian diet but occasionally consumes fish or meat. 
In New Zealand, dairy production has placed stress on soils and greenhouse gas (GHG) emissions (Morris, 2013). The modern production of meat and dairy also requires high levels of water. A water footprint study of beef cattle and sheep farming in New Zealand - the country is the largest exporter of lamb in the world, accounting for around 47 per cent of global lamb trade - found that agricultural activity has significant water use, contributing to most of the water scarcity footprint (Morris, 2013).

Reducing the production and consumption of these high impact foods would reduce their environmental impact. Influencing our food choices can play a role in reducing the consumption and production of meat and dairy. Chapter 2 will examine the literature in this area.

Studying the influence of values- and ethics-based attitudes to meat and dairy consumption in New Zealand could contribute to addressing concern around food choices and their environmental implications. Growing up in the United Arab Emirates (UAE) - a country where religion and culture play a huge role in people's food choices, including meat and dairy consumption - made me question what defines our food consumption today. As a young child, my affection towards animals and plants was infinite; waking up at dawn as a five-year-old to feed the birds and watch Indian green parrots play around was fascinating. However, eating chickens for lunch was not a pleasure of mine. A chicken and a bird were not that different to me. My inquisitiveness about why I felt this way led me to my continuing interests in environmental protection, animal welfare and optimum health. The UAE has a vast range of cultures and cuisines from all around the world, since 88 per cent of the population is comprised of expatriates (GMI, 2020). This exposure to various cultures and cuisines revealed different ways of thinking to me, which sparked my interest in what drives our food choices, what defines them and how we justify the way we eat, especially in the case of meat and dairy consumption. 
Learning about the impact of our food choices on the environment showed me the importance of contributing to this area of research to help preserve our natural world.

Other writers think similarly. A number agree that it is the duty of human beings to maintain environmental ethics to prolong the viability of the Earth's ecosystem (Stenmark, 2017), raising many concerns regarding the future of the environment. According to Singer (2011), beef is 'extravagant', due to the high methane emissions that are involved in its production, along with the diversion of the grains that are fed to cattle instead of humans. Both effects put the world under environmental pressure.

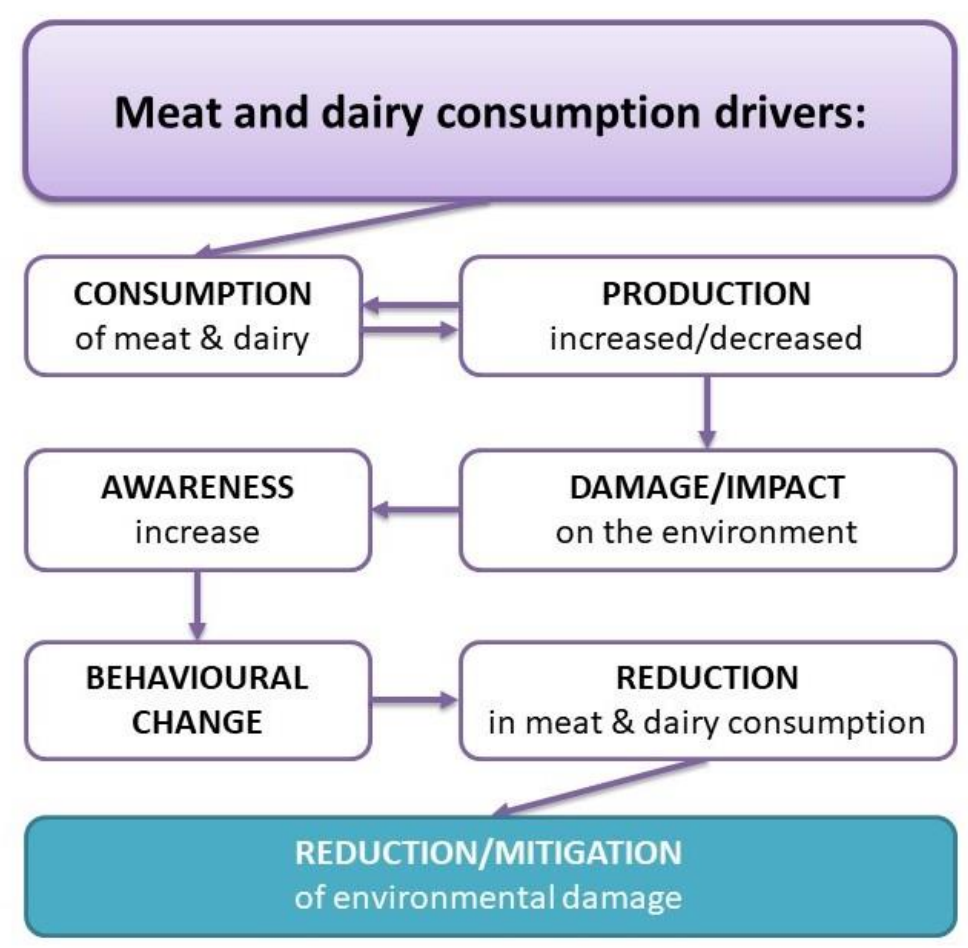

Figure 1.1. conceptual framework (developed by the author of this research)

The above conceptual framework (Figure 1.1.) was created to illustrate the aim of understanding meat and dairy consumption drivers as a way to encourage behavioural change, which in turn helps in achieving a reduction in meat and dairy consumption with the goal of reducing environmental damage. 


\subsection{Why focus on meat and dairy?}

While other factors are negatively affecting the environment, there is a dialectical relationship between market economy production and consumption (meaning one influences the other). This has a significant impact on the environment — starting from growing feed for cattle to the creation of meat and dairy products. Thus, one of the aims of this research is to have an in-depth look at the value- and ethics-based drivers of meat and dairy consumption. To my knowledge, the current literature does not contain this type of field study that explores the drivers of meat and dairy consumption in New Zealand.

Moreover, the drivers that influence people's attitude towards meat and dairy consumption ultimately have an important bearing on reducing the impact of meat and dairy industries on the environment. Thus, aiming to understand these drivers will help contribute to finding where and how to create awareness as a solution to reduce environmental degradation.

Meat and dairy consumption, especially that of meat, is currently regarded as one of the prime drivers leading to the sixth mass extinction. 4 The 2019 IPBES Global Assessment Report on Biodiversity and Ecosystem Services revealed that intensive agriculture, also known as industrial agriculture, and overfishing were the leading causes of biodiversity extinction, with meat and dairy specifically identified as having a substantial impact (Diaz et al., 2020).

The impact of meat and dairy consumption on the environment is immense, which renders it urgent and of intense importance to address in order to conserve the environment. Yet, research shows that those who avoid meat and dairy are the minority globally, even with a high number of others indicating they might be willing to change their meat and dairy consumption for environmental reasons. For instance, in the United States and the United

4 The sixth mass extinction is also known as Holocene extinction or Anthropocene extinction. 
Kingdom, vegetarians account for less than five per cent of the population. At the same time, those who are aware of the impact of meat and dairy consumption on the environment in a number of similar countries - the United States as well as Belgium, Finland, Germany, the Netherlands and Portugal - ranged between 23 per cent and 35 per cent (Sanche-Sebate and Sabate, 2019).

\subsection{Research gaps}

Having an in-depth understanding of what guides people's food choices will allow an understanding of consumers' perceptions of the environmental effects of meat and dairy consumption. This will lead to a recognition of ways to effect behavioural change. However, currently, there has been no qualitative research into how values and ethics influence individuals' decisions around meat and dairy consumption in New Zealand.

The choice to focus on meat and dairy consumption came from the significance of these sectors' effects on the environment. Although there have been numerous studies on how industries affect the environment as well as the various methods to limit their environmental impact and waste production, not many have focused on directly influencing meat and dairy consumption as huge contributors to environmental degradation. Thus, finding out people's attitudes towards meat and dairy consumption will provide crucial information on the drivers that are increasing the rate of production. With this knowledge, further research will then be required to find out how these attitudes can be addressed to create awareness surrounding the impact of meat and dairy consumption on the environment, thereby encouraging behavioural change. 


\subsection{Research aims and questions}

This research aims to contribute to environmental conservation by exploring the underlying causes of meat and dairy consumption that result in environmental degradation. The overall purpose of this research is to:

1. understand how some people in New Zealand society perceive values- and ethicsbased issues of meat and dairy consumption and implications for the environment

2. contribute to research on attitudes around meat and dairy consumption that may address behavioural changes based on the environmental consequences of meat and dairy consumption.

The proposed method in this research focuses on specific groups of people identifying with either a domain-specific value driver or an ethics-based driver concerning meat and dairy consumption, in which further discussion of those drivers are discussed in the literature review. It also discusses the environmental implications of meat and dairy consumption choices made by people that identify with these drivers. The focus on domain-specific values came after observing the common drivers people have when making their decision, conscious or not, to consume meat and dairy. Ethics-based drivers are reflected in current trends, including the research and statements by environmentalists who recognise the damage caused by meat and dairy consumption choices.

Besides finding out more about the drivers influencing people's attitudes towards meat and dairy consumption, this research aims to find out the current level of awareness of study participants about the impact that consuming meat and dairy has on the environment. Further, this research intends to explore the relationship between the drivers that influence people's attitudes towards meat and dairy consumption. The study aims to answer the following questions: 
- What ethics- and value-based drivers are perceived by people in society to influence their meat and dairy consumption?

- How do interviewees perceive the environmental implications of meat and dairy consumption?

- How can findings from the research inform behavioural change?

The overview below (Figure 1.2.) shows the most important components of this research, which summarises what, how and why this research came to place, including the research questions.

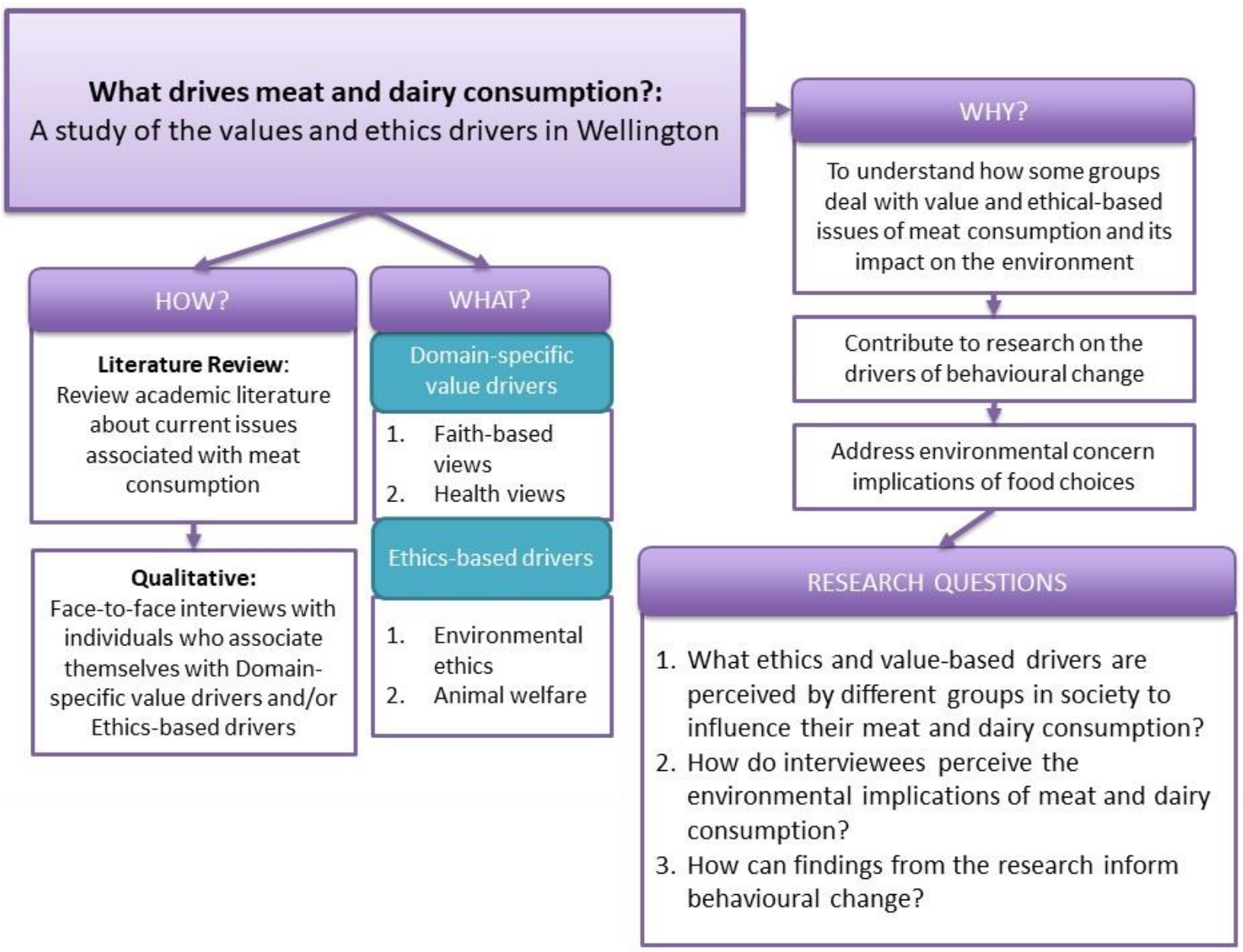

Figure 1.2. Process overview. (developed by the author of this research) 


\section{Chapter 2: Literature Review}

\section{Eating is a scandal at the heart of human life.}

Alec Irwin, 'Devoured by God' (2001)

The complexity of eating and how shocking it can be is expressed well by author Alex Irwin who wrote these words in his chapter 'Devoured by God: Cannibalism, mysticism and the ethics in Simone Weil' in CrossCurrents. He looked at eating as destructive to that which was consumed, by making other beings die for us to live, thus fulfilling the human desire. $\mathrm{He}$ also emphasised the fact that eating annihilates humans as independent entities. This literature review aims to explore a number of attitudes around meat and dairy consumption in New Zealand. It begins by identifying key terms relevant to the research and showing the differences between them. The literature on both domain-specific and ethics-based drivers helps identify the basis of people's meat and dairy consumption attitudes.

\subsection{Background}

Individuals in New Zealand and across the globe are increasingly becoming aware of how their food choices affect the environment. The drivers that prompt individuals to make these choices have attracted the attention of scholars and policymakers. For this particular research, the drivers of meat and dairy consumption that I have chosen to investigate are domain-specific drivers and ethics-based drivers. These drivers were selected to explore the most critical attitudes that play a significant role in defining people's meat and dairy consumption attitudes, for the purpose of influencing these attitudes towards more environmentally-friendly behaviour. 
This research explores two aspects of the domain-specific drivers, which are:

1. faith-based attitudes around meat and dairy consumption, which explores faithbased beliefs (e.g., Christianity, Islam and secularism)

2. health-based attitudes around meat and dairy consumption, which show how one's personal health and attitudes around ideal health drive their meat and dairy consumption habits.

The ethical-based drivers in this research are:

- environmental ethics, which looks at the ethical aspect of the environmental issues surrounding meat and dairy consumption attitudes

- animal welfare, which looks at attitudes related to meat and dairy consumption from an animal welfare perspective.

\subsection{Key terms associated with values and ethics}

Values are widely considered to guide our behaviour. Schwartz (2012) and Rokeach (1973) described values as trans-situational, enduring methods of behaviour. Vinson, Scott and Lamont (1977) categorised values influenced by beliefs relevant to social, economic, religious and other activities as domain-specific values. According to Abrahamse (2019), research findings indicate that interventions that are aimed at encouraging a reduction in meat and dairy consumption should take drivers such as values, identity and attitudes into consideration.

Although the terms' values', 'ethics' and 'attitudes' can appear similar in certain respects, it is essential to distinguish the differences between them. Values define moral principles or standards of behaviour. They are directly influenced by friends, culture, religion and social interactions (Chippendale, 2001). Values dictate what is important. Ethics focus on what is right and are based on moral values. Ethics are built on honesty and compassion. Both values and ethics define a person's attitude. Attitudes are simply opinions about certain subject 
matters; an attitude defines a person's personality and highlights their behaviour (Chippendale, 2001). Attitudes are both directly influenced by a person's values and ethics. Figure 2.1 demonstrates the relationship between values, ethics and attitudes.

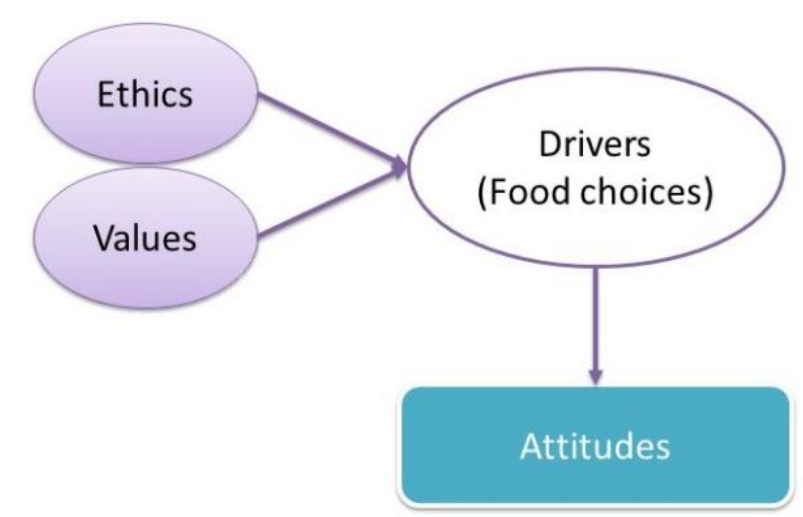

Figure 2.1. The relationship between values, ethics and attitudes. (developed by the author

$$
\text { of this research) }
$$

The table below (Table 2.1) below provides definitions of key terms that are useful in understanding the values and ethics around food consumption; they help provide an understanding of how meat and dairy consumption attitudes are formed.

\section{Table 2.1. Definitions of key terms}

Values Rokeach (1973) and Schwartz (1992) considered values as transsituational, enduring methods of behaviour. Some values can be centrally-located with a person's belief system; therefore, they are closely related to the self (Verplanken \& Holland, 2002). These values are considered to guide our behaviour, but are very abstract, which makes it challenging to find a direct relationship between values and attitudes (Jerry \& Vaske, 1999). The second type of values explained by Vinson is domain-specific values. These values are influenced by beliefs relevant to social, economic, religious and other activities in which personal beliefs influence attitudes. 
Intrinsic values Also known as self-actualisation values, Roe, Schwartz and Surkiss (1999) explained that intrinsic values directly express openness to change values. Further, Chan et al. (2016) expounded that an object's intrinsic value is the instrumental worth that is derived from its ability to produce something else. This value is vital to morality since most people advocate for the promotion of intrinsic goods and are detractors of evil. Chan et al. further argued that an earthquake is intrinsically wrong since it causes suffering to many people, and although something no human being can control, it is still intrinsically wrong. A thing is intrinsically good if it produces something useful.

Domain- $\quad$ Oppedijk van veen and Verhallen (1986) described domain-specific specific values values as a cluster of beliefs that guide behaviour specific situations within a domain of activities. The different domains include religion, politics, economy, work and consumption. Another theory suggests that individuals tend to value those domains in which they have staked their self-esteem (Crocker and Wolfe, 2001), predicting current and future activity choices (Eccles and Harold, 1991; Eccles and Wigfield, 1995).

Ethics Kagan (1992) considered ethics to be a moral framework that influences the decisions that people make in their lives. Ethical values embody what is right for both individuals and the societies in which they live. The term is an English derivative of the Greek word 'ethos', which means a disposition or habit (Kagan, 1992). Broadly, the term encompasses human beings' rights and obligations, moral decisions, 
and how to lead a good life. Ethics are acquired from various agents of socialisation such as religious institutions, close relatives and society. The subsets of ethics include applied ethics, normative ethics and meta-ethics (Kagan, 1992). Vogel and Wanke (2016) defined attitudes as a longstanding system of beliefs that affect a person's disposition about a thing or person. Attitudes influence the constant dispositional readiness to react to certain situations in a certain way, which later becomes one's natural response to similar situations. According to Vogel and Wanke (2016), attitudes comprise of affective (emotional), behavioural and cognitive (knowledge) components. An essential characteristic of attitudes is their principle of consistency, which postulates that people expect others to behave in a certain way in different contexts due to their attitudes (Vogel and Wanke, 2016).

Food choices According to Kroese, Marchiori and de Ridder (2015), food choice refers to the process of deciding what foods to buy and eat. Various drivers determine the choice of food for consumption, such as culture, price, allergies, preferences and health. Additionally, some people choose foods based on their habits, moods, appetite, brands, taste and ease of cooking, among other drivers (Kroese et al, 2015).

Beliefs Beliefs are convictions and assumptions that people hold to be true regarding events, people and things (Karwowski and Barbot, 2016). When a person places their trust in a being or thing, the person is considered a believer of the being or thing. A person's own beliefs are 
found in the person's experiences, cultural norms and their education.

When one considers their beliefs as being truthful, one will defend it and incorporate it as part of their belief system (Karwowski and Barbot, 2016). One's beliefs form their values and shape their attitudes.

Food

sustainability According to Godfray et al. (2014), sustainable food is food that does not affect the health of the consumer. Such food is devoid of pesticides, harmful antibiotics and genetic modifications. Additionally, the growth of the plants and rearing of the animals can be considered sustainable if the farming activities do not strain natural resources (Lamine, 2015). Fundamentally, sustainable food production impacts the environment only minimally.

\subsection{Domain-specific value drivers}

For a long time now, psychological research has been concentrating on explaining specific behaviours. General values are not very well-suited to explain specific behaviours, so domain-specific values were formulated to do so. Domain-specific values were identified by Eimers et al. (1994) as the mental representations of vital life goals that consumers are trying to achieve within a certain domain.

In exploring the influence of various domains, the theory of planned behaviour explains the rationale behind certain choices. According to Abrahamse (2019), the theory offers insight into some of the drivers of human choice concerning travelling and food. The theory of planned behaviour posits that human behaviour is a function of people's intention to undertake a particular course of action. First proposed by Ajzen (1988), the theory of planned behaviour is one of the most widely accepted models of the belief-attitude-behaviour relationship within the health literature (Ogden, 2003). The significant beliefs that inform the desired direction of 
action include behavioural, normative and control beliefs. Behavioural aspects refer to the perceived positive or negative effects of engaging in a given behaviour and the nature of evaluation that people receive from taking part in such behaviour. The interactions between the aspects build on the attitude of an individual seeking to engage in such behaviour. The attitude towards such behaviour can be assessed by evaluating the level of agreement in individuals on how likely they are to take part in certain practices.

Abrahamse (2019) proposed that normative beliefs include the perceived expectations and conduct of people regarded as important, combined with an individual's motivation to comply with such expectations. The subjective norms entail the degree of social pressure that individuals receive to conform to the standards. For instance, an individual would consume a specific meal because people who are essential to them expect them to. Moreover, controlled beliefs relate to drivers that can influence the extent to which an individual can take part in a specific behaviour. Such drivers include time, money, skills and individual abilities that can impact their likelihood of them taking part in such behaviour.

Abrahamse (2019) further proposed that the behavioural intentions of individuals reflect the inclination of individuals to share in each course of action. The theory of planned behaviour offers insight into the barriers and facilitators of environmentally-significant behaviour. Abrahamse (2019) summed up that people with more favourable attitudes towards a behaviour and those who receive a more robust endorsement from others are more likely to take part in a given behaviour. In the case of food patterns, the theory of planned behaviour has a considerable influence on the food choice of individuals.

Abrahamse (2019) explained that targeting people's domain-specific values is one way of understanding people's altruistic motivations towards environmental implications, and it is then possible to apply the theory of planned behaviour to encourage behavioural change. The two chosen domain-specific drivers for this research are faith-based attitudes and health-based 
attitudes towards meat and dairy consumption. I chose these two attitudes as domain-specific attitudes because they play a significant role in defining a person's value, therefore, allowing an understanding of their altruistic motivations. The following section will outline the extant literature on how faith-based and health-based attitudes drive people's meat and dairy consumption.

\subsubsection{Faith-based attitudes towards meat and dairy consumption}

Our beliefs play a vital role in determining our food choices, and research by Azam (2016) reveals that religious teachings are influential in these choices. For example, Islam does not allow Muslims to consume pork, some Catholics do not eat meat during periods in their faith calendar, and many Jews abstain from all eating and drinking on specific days. According to Fuccillo, Sorvillo and Decimo (2016), who explored law, religions and food choices, there is significant evidence supporting the claim that religiously-prescribed traditions influence dietary habits. When it comes to the world's largest religions, this can have a significant effect on the environment. Yet, food choices made for religious reasons can often be disconnected from their environmental impacts. Many recent studies have shown the impact meat production has on the environment-Grossi et al. (2019) state that livestock production, in particular, contributes to global warming through emissions of methane and nitrous oxide- - however, some religious individuals, for a variety of reasons, are not necessarily fully aware of the relationship between food choices and environmental protection. Further, some religious practices today are often arguably not in line with the actual teachings of that religion. For instance, Islamic teachings are extremely specific in terms of the importance of protecting the environment, and yet Islamic countries often have high environmental degradation. The study by Fuccillo et al. (2016) showed that the number of Muslims around the world might be almost 
equal to Christians by 2050, potentially increasing both the halal slaughter market and environmental damage, due to deforestation to increase meat production.

Religion bequeaths values that have an impact on how individuals relate. A study by Vinson et al. (1977) pointed out that religious values play an essential role in marketing and consumer behaviour, proposing a system to categorise values and their effects. The different categories of value have a significant influence on the behaviour of consumers. In comparison, domain-specific values are acquired through experiences in specific situations. Such values cannot be explicitly understood outside the context of a particular environment. Also, Chuvieco, Burgui and Gallego-Álvarez (2016) proposed that religious beliefs and values have a considerable bearing on environmental concerns, as religion offers a cosmological view on how humans should relate to other creatures.

Faith-based attitudes influence people's identity. Correspondingly, an individual's religion influences the nature of the choices they make. In exploring the drivers that are related to meat consumption, Abrahamse (2019) pointed out that self-identity plays a considerable role in influencing food choices. Self-identity is defined as an individual's adoption of a particular group, which covers the uniqueness of a person depicted through their values, attitudes and opinions. A close correlation exists between self-identity and food consumption.

Religious beliefs have played an immense role in shaping the world, and the belief or interpretation shared by the three major monotheistic religions-Judaism, Christianity and Islam - that God created human beings and the Earth for the benefit of humans, has been highly influential. Ethicists point to a significant source of this viewpoint in the Book of Genesis in the Bible (and Jewish Torah), which states that humanity was created in the image and likeness of God. God instructs humans to subdue and have dominion over all animals and plants, suggesting that human beings can exploit other creations for their benefit (Kopnina et al., 2018). 
And God said: 'Let us make man in our image, after our likeness; and let them have dominion over the fish of the sea, and over the fowl of the air, and over the cattle, and over all the earth, and over every creeping thing that creepeth upon the earth.' And God created man in His image, in the image of God He created him, male and female created He them. And God blessed them; and God said to them: 'Be fruitful, and multiply, and fill the earth, and subdue it; and have dominion over the fish of the sea, and over the fowl of the air, and over every living thing that creepeth upon the earth.' (Genesis 1:26-28, King James Version)

Ethicists like Peter Singer have criticised this view. Singer examined the meaning of dominion in the Book of Genesis, holding the text partly responsible for adverse Western attitudes to nature (Beed and Beed, 1998). However, Beed and Beed (1998) argued that the Biblical text on 'dominion' is to be understood as humans ruling the Earth on God's behalf, as his representatives. The concept of 'dominion' includes stewardship and preservation of the natural environment. Religious texts can, of course, be interpreted in different ways. Also, some passages in religious texts may, or may seem to, conflict with or even contradict passages in other sections of the same text. Other faith-based values can also influence a person's interpretation of their faith-based drivers of food choices as chapter 4 of this research will illustrate.

Although religious practices are considered a faith-based attitude, secularism can be identified as such as well. Secularism is a philosophical approach that seeks to interpret life from the physical world alone. Scholars, however, have expressed the view that secularism is a form of religion itself (Yinger 1967). Although widely used as the antithesis of religion, Yinger (1967) elaborates that secularism is not truly so, but rather—like religion — a system of beliefs and practices people use in relation to human life. 
Some secularists argue that religious guidance could reduce perceptions of risk urgency when it comes to material matters such as climate change or the environment generally, as secularists see religion as having a more relaxed attitude around environmental degradation compared to secularist views. This is due to the beliefs in an afterlife and divine intervention (Hope and Jones, 2014). Hope and Jones (2014) investigated the differences in proenvironmental values and beliefs between Christians, Muslims and secular participants, contributing to the dialogue about the role that religious faith might play in shaping opinions about climate change and the acceptability of proposed policies for mitigation and adaptation (Hope and Jones, 2014).

The arguments presented above demonstrate why faith-based attitudes (including secular attitudes) are important to address as a meat and dairy consumption driver, since faith influences people's identity and attitude as well as shaping the way we deal with environmental issues associated with our meat and dairy consumption choices.

\subsubsection{Health-based attitudes towards meat and dairy consumption}

Meat is one of the most favoured food types in the world. In recent times, the consumption of meat has been on the rise with a five-fold increase in global meat production since 1961 (Ritchie and Roser, 2017). According to Ritchie and Roser (2017), each type of meat, including beef, chicken, pig and goat meat, has seen a massive increase in production as the world's population has grown each year. Furthermore, per capita consumption is also increasing in areas where people can afford meat. As explained by Popkin (2009), per capita intake is already much higher in high-income countries so the growth in per capita intake is essentially found only in lower-income countries (Popkin, 2009).

Proponents of meat consumption cite nutritional benefits and taste as the main reasons why human beings consume meat (Fuccillo et al., 2016). However, increasingly, scholars have 
discussed the adverse effect meat and dairy intake has on our health. Although meat and dairy consumption can provide important vitamins and minerals, the adverse effects outweigh the food's benefits. According to the International Agency for Research on Cancer (IARC), a World Health Organization (WHO) affiliated organisation, red meat is 'probably carcinogenic to humans' and leads to cancer development through oxidative stress factors that occur during the digestion process (Myung-Bae and Chun-Bae, 2020). Moreover, the nutritional benefits can be obtained from other food groups. Therefore, a growing number of people today prefer a meat-free diet for health benefits, as well as to promote biodiversity and as a means to control and decrease their carbon footprint. For example, a study by Seves, Verkaik-Kloosterman, Biesbroek and Temme (2017), in which meat and dairy were replaced by plant-based alternatives, found that there is room to reduce meat and dairy intake without compromising nutritional adequacy, and this dietary change would also benefit environmental sustainability.

Friel et al. (2009) highlighted the correlation between meat consumption and cardiovascular diseases. Increasing cases of cancer also correlate positively with increasing cancer cases across the globe (Ferguson, 2010). In comparison with other OECD countries, New Zealand, which has high rates of meat and dairy consumption, has the highest incidence of colon cancer and the second-highest rate of breast cancer (Ferguson, 2002). However, despite the dangers associated with increased meat consumption, Fiala (2008) pointed out that the demand for meat products has been rising steadily.

Health-conscious individuals note the importance of monitoring what they eat to live a healthy lifestyle. At the same time, a diet based mostly on plants can support the environment. Perignon, Vieux, Soler, Masset and Darmon (2017) argued that the adoption of a vegetarian or a vegan diet protects both human health and the environment. Foods of plant origin exert a lower environmental impact than animal-based products and adopting a vegetarian or a vegan diet shows better overall health compared to a diet that includes the consumption of meat and 
dairy. Self-selected diets with better nutritional quality are characterised by a predominance of foods with low greenhouse gas emissions (Perignon et al., 2017).

Mitigating adverse effects requires strategies that incorporate the food and agriculture sectors. Regions that practise large-scale livestock keeping are more prone to deforestation, loss of diversity, pollution of available freshwater, and leaching of excess nitrogen.

A New Zealand study by Hughey, Kerr and Cullen (2016) pointed out that the single most important environmental concern among the local population is freshwater quality and its related issues. Dairy production is New Zealand's largest agricultural industry. Foote and Joy (2014) highlighted the danger of nitrogen as one of the significant wastes from dairy farming. Not only does it lead to extensive deterioration of freshwater, killing wildlife and poisoning water supplies, but it also carries an enormous cost unpaid by the polluter. For example, McMichael (2013) stated that regions such as Vietnam, Egypt and Iraq face deprivation, displacement and conflicts that arise from lack of fresh water, which poses various risks, including health risks to the general population. Production of meat and dairy is one of the reasons for the freshwater loss, and both the shortage and pollution of freshwater puts human health at risk. Ritchie and Roser (2017) revealed in their study that one of the strongest determinants of how much meat people eat is how rich they are, furthermore, the study showed that countries are becoming richer compared to the year 1990.

\subsection{Ethics-based drivers}

Ethics concerns the moral right or wrong of an action. It serves to promote absolute values, while, at the same time, discourage individuals from engaging in immoral behaviour (Chmielewski, 2004). The two primary components of ethics-based attitudes towards meat and dairy consumption are environmental ethics and animal welfare. 
Singer (2011) pointed out how practical ethics manifest in the values of a community. For instance, Western traditions, which come primarily from a blend of cultures of the early Judeo-Christian tradition and ancient Greek philosophy, contrast deeply with other ancient traditions such as those of India. Members of different societies are likely to incline to their perceptions of practical ethics and values that will manifest in their food choices. The understanding of practical ethics, however, varies considerably across cultural divides (Alam, 1993). For example, Wines \& Napier (1992) explained that the understanding of practical ethics differs between traditions due to neglect in the study of cross-cultural ethics, which discusses the issues of two cultures in different contexts. These issues have not usually been considered because of the complexity of ethics (Wines \& Napier, 1992). Therefore, Herzog and McGee (1983) stated that the challenge of developing operational measures for such cross-cultural concepts can be daunting.

Ethics is an important part of defining one's belief system and morals. This is especially the case for environmental ethics and animal welfare since both attitudes have a huge impact on shifting people's meat and dairy consumption towards more environmentally-sustainable behaviour. A study by Sanchez-Sabate and Sabate (2019) found that animal welfare and environmental concerns play a role in converting people to a vegan or a vegetarian diet. However, the number of converts was not high, despite the vegan diet receiving increased media attention in recent years (Sanchez-Sabate and Sabate, 2019). The two primary components of ethics-based attitudes towards meat and dairy consumption are environmental ethics and animal welfare.

\subsubsection{Environmental ethics attitudes towards meat and dairy consumption}

Environmentalists believe that human beings play a prominent role in the conservation of the environment and the sustainability of the ecological systems that support the Earth's flora 
and fauna. The environment, and the plants and animals that it supports, forms a vital part of human life. Environmentalists argue that, from an ethical basis, human beings are obliged to treat plants and animals with respect to sustain the environment. Planet Earth suffers from pollution, global warming and overconsumption of energy, and human beings must work to prolong the viability of the Earth's ecosystem (Stenmark, 2017).

The EAT-Lancet Commission on Food, Planet and Health has undertaken significant research on many aspects of sustainable diet strategies and their association with environmental impacts, emphasising the importance of replacing animal-sourced foods with plant-based ones to reduce environmental impacts, particularly greenhouse gas emissions (Springmann et al., 2018). However, this requires behavioural change. A study by Westhoek et al. (2014) on the effects of cutting Europe's meat and dairy intake found out that lowering livestock production would lead to 25 to 40 per cent lower greenhouse gas emissions by replacing 25 to 50 per cent of current meat, eggs and dairy consumption in the EU with plant-based foods (Westhoek et al., 2014).

Behaviour change campaigns influence the nature of choices that individuals make. According to Abrahamse (2019), behaviour change interventions offer insight into the drivers that influence the decisions made by individuals in the community. Structural interventions involve modifying the context in which individuals make vital decisions in their lives, and that is facilitated by technological innovations, policy changes and infrastructural changes. The primary motivation behind the technique is to encourage individuals to change their demeanour through changing structural levers. For instance, increasing the cost of practices that hurt the environment and decreasing the cost of those that are friendly to the environment is likely to influence change in the conduct of individuals. Abrahamse (2019) suggested that increasing fuel taxes is expected to encourage individuals to reduce their car use and install solar panels. 
In a similar way, taxing certain foods and beverages is likely to discourage the population from consuming such items.

Informational interventions focus on altering the determinants of environmentallydestructive behaviours, which is a goal that is attained by fostering people's knowledge, attitudes and beliefs. For instance, promoting information on the adverse effects of climate change is likely to influence change in the pattern of activities that contribute to global warming. Ripple et al. (2014) cautioned that massive cuts in the production of carbon dioxide might not be sufficient to abate climate change. They proposed the need to reconsider ancient traditions such as large-scale livestock operations, biomass burning and other traditions such as rice production. Similarly, informing people about the dangers of certain food products such as junk food and beverages high in sugar influences the likelihood that they will change their eating habits and begin consuming healthy meals. Reinforcing this information with possible reward ensures that individuals are more committed to adopting positive behaviour.

According to Willett et al. (2019), the acceptance of healthy diets from sustainable food systems will help achieve the United Nations Sustainable Development Goals and the Paris Agreement. The Paris Agreement is an accord between 197 countries and is the new global agreement on climate change. It aims to limit global warming to well below $2{ }^{\circ} \mathrm{C}$. The United Nations Sustainable Development Goals aim to protect the planet and ensure that all people enjoy peace and prosperity by 2030. Willett et al. (2019) observed that a transition to healthy diets by 2050 would require a substantial dietary shift with a reduction of more than 50 per cent in the global consumption of unhealthy food such as red meat and sugar. Willett et al. (2019) further proposed that dietary shifts are likely to play a considerable role in reducing the 11 million deaths every year that are associated with unhealthy eating patterns. Also, the transformation will lead to a 75 per cent reduction in the yield gap and promote global 
redistribution in the use of nitrogen and phosphorus fertiliser. Such a shift will save the environment from the adverse environmental effects of the leaching of these nutrients.

A change in national policies to promote ethical practices in the management of the environment may influence the actions of individuals. According to Wilson et al. (2013), the food choices of individuals are affected by prevailing government policies and product promotion measures. The study findings relate to the context of New Zealand. It was discovered that offering vouchers for food from supermarkets influenced the selection of healthy items. The study proposed that the ideal process of identifying optimal foods requires an in-depth consideration of cultural appropriateness and the need to avoid stigmatisation. It also introduced the use of fiscal and monetary policies in influencing dietary shift patterns. McIntyre and Dutton (2015) offered insight on several nutritional guidelines adopted by the New Zealand government. New Zealand residents are encouraged to enjoy a variety of nutritious foods that include grain foods, vegetables, fruits and milk products. According to Drew (2018), the move by the government of New Zealand to develop eating and activity guidelines presents an opportunity for the development of public policy that includes sustainable options. Moreover, study by Jones et al (2019) that evaluate the agreement among sectoral professionals of including sustainability characteristics within New Zealand's eating and activity guidelines found that professionals from the agriculture, environment and health sectors largely support the inclusion of sustainability characteristics in New Zealand's Eating and Activity Guidelines, however, it requires a multi-sectoral approach to address areas of divergence (Jones et al., 2019).

Willett et al. (2019) additionally cautioned that the absence of scientific targets for achieving a healthy diet from sustainable food systems hinder large scale and coordinated efforts in the transformation of the global food system. 
Ethical conservations is another reason why some individuals are thoughtful in their food choices. Dowd and Burke (2013) observed that the increasing popularity of animal ethics has contributed to the increased number of vegans and vegetarians in the United States. A study by Radintz et al. (2015) revealed that ethical vegans6 follow their diet longer than health-motivated vegetarians. Ethical vegans gain health benefits as well, which motivates them to strengthen their observance of, and adherence to, animal rights. Ethical vegans are people who refrain from the consumption of meat/animal products for ethical reasons, such as animal welfare and environmental concerns.

The ethics of eating extend beyond the reduction of the consumption of animal products. According to Singer (2005), eating, or more specifically, paying for what we eat, is part of a vast global industry. Americans alone spend more than one trillion dollars on food every year, which is more than double the amount spent on motor vehicles. Food production impacts every person on Earth and billions of animals as well. We may conclude that eating has profound implications for the environment, animals and future generations: food choices raise important ethical issues, and humans would benefit from carefully considering the impact of what they eat.

Additionally, environmentalists have raised concerns about the high nitrogen and greenhouse gas emissions that result from livestock rearing (Lamine, 2015). The increased demand for meat within the populations of developed countries resulted in the advent of factory farming. Numerous studies have sought to document the adverse health and environmental

5 Ethical conservation: is the ethic of resource use, exploitation and protection. It focuses on the maintenance of the natural world.

6 Ethical vegans: People who follow a vegan lifestyle that excludes all forms of exploitation and cruelty to animals for food, clothing or any other purposes. 
effects of eating mass-produced meat and dairy products, as pointed out in the previous sections. Ethicists and ethical vegetarians in developed countries point to the negative impacts of meat and dairy consumption on animals and the environment. As a result of increased demand for livestock production, large areas of forest land are cleared to raise livestock. According to a World Wildlife Fund report (2017), the clearing of land for large-scale animal feed production accounts for 60 per cent of biodiversity loss every year. Furthermore, livestock rearing is responsible for at least 20 per cent of greenhouse gas emissions globally (Clonan, Roberts and Holdsworth, 2016). Consequently, livestock farming represents the most significant contribution from a single human activity to greenhouse gas emissions and climate change. For this reason, some individuals choose to become ethical vegetarians and avoid animal products entirely.

New Zealand has a high level of meat and dairy consumption per capita and the resulting production process has impacted the country's environment. In 2014, agriculture as a whole was responsible for 48 per cent of New Zealand's greenhouse gas emissions (Tucker, 2018 and Environment Aotearoa, 2019). As a result, reducing the environmental impacts of meat production has been high on the agenda of New Zealand's government. One of the suggested ways to curb the effects includes reducing domestic meat and dairy product consumption. It might be argued that since most of the product is exported, the impact of this may be modest, nevertheless, understanding the values and ethics that surround meat and dairy consumption in New Zealand can be useful in terms of achieving the goal of reducing its negative impacts on the environment.

Sustainable eating is not easy (Abrahamse, 2019). It is a shared encounter in which individuals have concerns about which products are better, their origin and the circumstances that surrounded the packaging of the products. The Food and Agricultural Organization (2018) defines a sustainable diet as one with a low environmental impact that also contributes to food 
and nutritional security. Additionally, sustainable diets promote healthy lives for present and future generations. Moreover, they protect biodiversity and ecosystems, and they are culturally acceptable. Many health and nutrition specialists have explored drivers that motivate individuals to make confident food choices, moving beyond health campaigns that simply encourage people to eat healthy diets and include fruits and vegetables in their meals. Abrahamse (2019) pointed out that industrial animal agriculture contributes to the generation of greenhouse gases such as methane, carbon dioxide and nitrogen oxide. Similar assertions are supported in a study by Grossi, Goglio, Vitali and Williams (2019), which linked livestock with increasing levels of greenhouse gases. Also, Baldini, Bava, Zucali and Guarino (2018) pointed out that measuring emissions from manure management activities is a challenging task due to complicated temporal variability in the processes that result in the emission of greenhouse gases.

A significant portion of the global population is ignorant of the adverse impact of meat and dairy consumption on the environment. Heightened awareness in such issues could help induce a change in the dietary patterns of developed countries. For instance, the rise in "parttime vegans' is strongly associated with increased awareness of the effects of consuming animal products on the environment. According to Deckers (2010), increased awareness of veganism could help control the adverse effects of livestock on the environment. In exploring the values and beliefs of vegetarians, Allen, Wilson, Ng and Dunne (2000) proposed that vegetarians are less likely to endorse hierarchical domination. They are expected to place more emphasis on the emotional considerations of other beings. However, Bechtel (2010) claimed there is limited awareness of how food consumption patterns hurt other beings and the environment. Additionally, most individuals are not familiar with the carbon cycle. There is also a tendency to shift the blame towards other drivers as opposed to humans taking responsibility for the 
activities that contribute to global warming. According to Bechtel (2010), the knowledge gaps reflect an unwillingness to accept climate science and not necessarily a lack of awareness.

\subsubsection{Animal welfare attitudes towards meat and dairy consumption}

Concern for the welfare of animals is one of the reasons why individuals choose not to consume meat. From the perspective of vegetarians or vegans, animals can feel emotions such as joy and grief. As a result, they believe that utilitarian ethics should apply to the treatment of animals (Rowlands, 2013). Utilitarian ethics is referred to as utilitarianism7, which was developed by the English philosopher Jeremy Bentham.

Since animals are conscious and emotional beings capable of feeling pain, the ethical considerations that apply when treating fellow human beings apply to the treatment of animals. For example, animal farming can be regarded as unethical and immoral since the practice only allows animals to live a fraction of their natural lifespan. According to proponents of animal welfare, it is immoral to cut short the life of an animal just because human beings enjoy the taste of meat. Since human beings are morally-bound, vegetarians choose to avoid meat and dairy products entirely for the sake of animal welfare.

Lindeman and Väänänen (2000) proposed different approaches to evaluating the motives of ethical food choices. They observed that ecological welfare, animal welfare and the desire for environmental protection have a substantial bearing on the moral food choices of individuals. Similar propositions advocated by Drew, Cleghorn, Macmillan and Mizdrak (2020) pointed out that dietary guidelines have the potential to promote substantial gains in health. Prescott, Young, O’Neill, Yau and Stevens (2002) further pointed out significant contextual

7 Utilitarianism is a collection of normative ethical theories that aims to maximise wellbeing and happiness through actions. 
differences that were specific to the New Zealand food system and did not appear to cause considerable deviation from the global trends.

The values of an individual affect one's appetite for meat. For instance, research by Benningstad \& Kunst (2020) on dissociating meat from its animal origins explains that the relationship meat-eaters have with the practice of killing animals for food is ambivalent. Making a clear connection between meat and animals has created dissonance for individuals that held strong animal welfare beliefs, yet still ate animal products (Benningstad \& Kunst, 2020). Therefore, the association between a person's values and their meat consumption hold true for many. In Europe, a study by de Boer and colleagues (2013) found a correlation between meat consumption and the values of an individual. Such studies affirm that an individual's values influence his or her attitude towards the consumption of meat. In contrast, research by Honkanen and Olsen (2009) pointed out that animal welfare issues concerning farmed fish did not seem to influence consumption in Valencia, Spain.

\subsection{Literature review summary}

The main issues highlighted in this review were the influence of domain-specific and ethical-based drivers on meat and dairy consumption. This review began with defining key terms that are useful in understanding the values and ethics around meat and dairy consumption. It discussed the relationship between faith-based attitudes and environmental degradation, and the influence meat and dairy consumption has on human health from a domain-specific value perspective. Ethics-based drivers look at how ecological ethics influence meat and dairy consumption habits, and how animal welfare inspires behavioural change in regard to meat and dairy consumption.

While this literature review covers various aspects of meat and dairy consumption drivers, further investigation is needed to gain information that includes awareness of 
environmental issues, the perception of values- and ethics-based issues concerning meat and dairy consumption, and the importance of establishing behavioural change. Although the literature emphasises the importance of shifting behaviour, further research is necessary to inform how behavioural change could be supported.

The literature review discussed the chosen four drivers that I believe most define people's attitudes around meat and dairy consumption. The literature in this area of research is vast and demonstrates the complexity of values, ethics and attitudes. Understanding people's insights on those drivers concerning environmental implications will help in understanding behavioural change and how to encourage it more in Aotearoa New Zealand. 


\section{Chapter 3: Methodology}

\section{An organism becomes a food only when created as such.}

David Goldstein, Eating and Ethics in Shakespeare's England (2013)

Goldstein claims that the role of food in early literature is not simply to eat, digest and excrete; rather it is the connection between the earth and humans, ideology and instrument. The values and ethics that drive our food choices are endless, but focusing on the drivers that most define our meat and dairy consumption would tackle most issues associated with their use.

Narrowing down the research on the chosen domain-specific values and ethics-based drivers enabled me to look at people's attitudes around meat and dairy consumption on a deeper, personal level. This chapter will talk about the method I chose to conduct this research, and why and how I chose my participants.

\subsection{Research epistemology}

Epistemology is the theory of knowledge, particularly its methods, validity and scope. My research epistemology is constructionist. According to Hughes (2012), constructivism views human knowledge as discovered, unlike objectivism, which believes that meaning and meaningful reality exist as such apart from the operation of any consciousness. Constructivism realises that people construct in different ways. There can be no unmediated grasp of the social world that exists independently of the researcher, and all claims to knowledge take place within a conceptual framework (Hughes, 2012). Moreover, Raelin (2007) described constructionism as applied practice in social theory to question the value of empirical data (Raelin, 2007). Empiricism is knowledge based on experience and experimentation, unlike rationalism, which is based on reason or logic. The information I am most likely to receive from my participants 
would be empirical, speculative or abstract, that is based on their experience around their meat and dairy consumption. Knowledge is built from scratch as new information becomes available, and we create our own reality through social interactions (Berger and Luckmann, 1966; Daft and Weick, 1984). My own views and values around meat and dairy consumption were shaped by information and knowledge that has become available to me over the years, in turn, helping me in writing this thesis. However, I do not claim to be impartial in this research. I approach it acknowledging my personal attitudes towards meat and dairy consumption. Prior to embarking on writing this thesis, it was a passion of mine to connect our domain specific-based value attitudes with environmental ethics and animal welfare, for the sake of our health and the environment. The reason for that being my own understanding of values and ethics that defined my attitudes. My religious values hold strong ethics related to environmental protection and animal welfare, hence the importance of connecting values with ethics is important in defining a person's attitudes.

A qualitative research method approach was used to collect data on people's values and ethics around meat and dairy consumption. Qualitative research allows a flexible study design that can be overwhelming at times. Flyvbjerg (2001) argued that research must combine intuition, experience and judgement. As the study explores the self-reflection of the participants, changes in interpretations must be taken into consideration. Context dependence is required to understand the open-ended relationship between actions, contexts and analyses.

Therefore, approaching this research using a qualitative research method will provide a more in-depth, personal look at people's attitudes around meat and dairy consumption. This will allow me to have an understanding of their ideas and motivations, and, ultimately, lead to an understanding of how their beliefs impact the environment and encourage behavioural change. 


\subsection{Research design}

This research used qualitative research methods. Flyvbjerg (2001) provided a strong argument for the importance of qualitative research, in which research focuses on values and moves closer to people and the experiences that motivate their daily practices. Silverman (2011) explained in his book Qualitative Research that this type of research method is as much about social practices as about experience. It is a theoretically-driven enterprise (Silverman, 2011). Qualitative methods aim to acquire a deeper look into the meaning behind the different food choices phenomena. In contrast, the approach of quantitative research methods aims to recognise broader trends that involve a larger number of people, and a more significant number of different values and ethics around meat and dairy. Furthermore, my own experience in exploring sustainable food choices and curiosity around people's choice drivers led to the design of this research. I decided to use a face-to-face interviewing method to collect my data.

\subsection{Interviews}

The target population for the study were residents in the city of Wellington, New Zealand, and aged above 18 years. I interviewed 13 participants who were interested in being part of the research. By the time I started my interview process, I had collected business cards and contact details of people I met while attending exhibitions and symposiums in Wellington. This allowed me to engage with people who had an idea of what my research was about and who agreed to give me their contact information. After receiving approval from the university's human ethics committee, I began by sending emails (Appendix D) to the contact details I had collected as well as contacting them through their social media platforms, which seemed to be the fastest way to receive a reply from them. Face-to-face interview was my method for collecting qualitative data, to gain a deeper understanding of the influence of critical drivers on meat and dairy consumption. After agreeing on the location and time to meet, a semi-structured 
interview style was used in collecting the data. As explained by Barriball and While (1994), semi-structured interviews are well suited for the exploration of the perceptions and opinions of respondents regarding complex and sometimes sensitive issues and enable probing for more information and clarification of answers (Barriball and While, 1994). Interviewing is considered one of the most effective methods used in collecting qualitative data. Miller and Glassner (2011) argued that in-depth interview accounts provide a meaningful opportunity to study and theorise about the social world. Interviews reveal evidence of the nature of the phenomena under investigation (Miller and Glassner, 2011). The questions I asked my participants were written based on the driver they identify with (Appendix C). General questions about participants' age and occupation were asked to start the conversation. Some prepared questions and topics of discussion were in hand, which helped in providing room for conversation and shared input between the interviewer and interviewee.

Generally, the interviews took between 45 minutes and an hour. The interviews were audio-recorded, and the participants were asked for permission to do the audio-recording of the interview (Appendix B). After asking them the general questions, the interview began by asking the participant which driver they mostly identify themselves with. Mostly, participants did not abide by one driver to explore; a few of them preferred to talk about two drivers that they could not separate as their primary meat and dairy consumption drivers. In some situations, I started my questions about one attitude, and after concluding them, we proceeded to the second set of questions. There were occasions on which the interviewee would link the previously discussed attitude in the interview with the second attitude of their choice.

Table 3.1. below shows a list of the participants, their pseudonym, age, gender and ethnicity. 
Table 3.1. Demographics of participants

\begin{tabular}{lcll} 
Pseudonym & Age & Gender & Ethnicity as described by participant \\
\hline Tere & 43 & Male & Māori \\
Belle & 53 & Female & Chinese \\
Mark & 60 & Male & Pakeha \\
\hline Adil & 51 & Male & Kuwaiti \\
Paige & 27 & Female & Pakeha \\
Sarah & 65 & Female & Pakeha \\
Simon & 42 & Male & British \\
Carla & 48 & Female & Māori-Pakeha \\
\hline Anwar & 33 & Male & Bangladeshi \\
\hline Omar & 34 & Male & Egyptian \\
\hline Zak & 44 & Male & Hungarian \\
\hline Darwin & 42 & Male & British \\
Warren & 24 & Male & Māori \\
\hline
\end{tabular}

\subsubsection{Data interpretation and analysis}

After the completion of the interviews, the process began with transcription of the interviews using Express Scribe Transcription Software, before I transferred the data to NVivo 12 Software for data analysis. The qualitative data were analysed using a narrative analysis method; this method includes a reformulation of information given by the interviewees taking into consideration the context of each interview and different drivers relating to the values and ethics of meat and dairy consumption. Qualitative data analysis helped in applying codes with non-quantifiable elements, including behaviours, activities and meanings, using the selective 
coding method to formulate a story by connecting the value and ethic-based practices around meat and dairy consumption.

\subsubsection{Ethics}

A submission to the Victoria University of Wellington Human Ethics Committee was made prior to conducting the interviews (granted on the 24th of January 2020). Prior to the agreement to conduct the interviews, the participants were given an information sheet (Appendix A) and a consent form (Appendix B) to read and sign as part of their agreement to participate. As the interviews focused on personal opinions for the study, interpersonal rapport was essential. Some of the interviewees felt the need to know my own position on meat and dairy consumption, which played a role in some of the interviewees' opinion input. Ultimately, the interviewees were not hesitant in providing their opinion on their meat and dairy consumption attitudes. This was also fostered by the confidentiality provided; before starting the interviews, participants were made aware that their identity would not be made public, and that pseudonyms would be used in the thesis to maintain confidentiality.

\subsubsection{Positionality}

I have been following a vegan plant-based diet since November 2010. My reasons for making this lifestyle change were related to health and ethics. As the years went by, I have stumbled upon information related to my own religious views that made me understand the importance of environmental protection and animal welfare. Most of my family members found my rationale to follow a plant-based diet unreasonable, and that gave me the inspiration to learn more about it and make it easier to for them to understand in their native language, Arabic. Some of my interviewees were very curious about what brought me to this research topic. Below is an example from my interview with Mark: 
Mark: One of your things was religious or cultural, is there a strong cultural religious effect in the UAE?

Interviewer: Oh yeah.

Mark: Yeah? So what religion are most people?

Interviewer: Muslim.

Mark: Mostly Muslims, yeah okay. And what does the Muslim religion say about the environment?

interviewer: A lot. It is a Muslim's duty according to Islamic teachings to protect the environment and to have compassion for the animals.

\subsubsection{Ethical principles}

As this was a qualitative study, it was necessary to construct moral principles and guidelines since it was crucial to enable harmonious interaction with interviewees while conducting the interviews according to the Human Ethics Committee's guidelines to avoid any potential harm to the participants.

The following were fundamental ethical principles that were used during the study. To reduce the possibility for harm to the participants, the interviews were carried out in places which the interviewee was comfortable with - in cafes and places of work. This aimed to remove both physical and psychological threats, and granted participants a social advantage to be able to communicate at ease with the interviewer. Another principle involved was asking their permission to be recorded before agreeing to do the interview, and letting them know that participation was voluntary; hence, they had the freedom to withdraw during the meeting at any time and for any reason, such as if they felt uncomfortable. 


\subsection{Methodology summary}

This chapter described the methodological approach to this research and outlined the steps I took to conduct my semi-structured interviews. It began with the research's constructionist epistemology and explained why a qualitative research method was chosen. The research design included the method of gathering participants, general information about them, and the number of interviews conducted. The interviewees were provided with an information and consent sheet before agreeing to their involvement in the research. The interviews were audio-recorded and held in the participants' place of choice. The interviews were transcribed using Express Scribe Transcription Software. and analysed using Nvivo 12 Software. Finally, ethics concern and positionality were important to address in this chapter to avoid false insights about the research 


\title{
Chapter 4: Results-Perspectives on meat and dairy consumption
}

\author{
Man is what he eats.
}

\section{Jean Anthelme Brillat-Savarin, The Physiology of Taste (1825)}

What we eat determines much of who we are as people, our health and our environment. Often expressed as 'You are what you eat', this quotation from Jean Anthelme Brillat-Savarin's 1825 book, The Physiology of Taste, or Meditations on Transcendental Gastronomy-a collection of reflections, recipes and stories on gastronomy-displays how throughout history, food has been seen to define a person. The results in this chapter show some aspects of how food choices define people, or rather how they define themselves based on those choices.

This chapter presents findings from interviews conducted with the 13 participants for this research. Twelve identified themselves with at least one of the drivers in the literature review; one was unable to identify with any, which will be discussed in chapter 6 . The chapter aims to provide qualitative results based on the findings of the interviews. In the following chapter, these results will be used to answer the research questions. The findings from domainspecific value drivers are presented to show the effects of faith-based and health-based attitudes on meat and dairy consumption. Ethics-based drivers are presented to address animal welfare and environmental ethics attitudes. The results of the interviews demonstrated some crossovers that illuminated the participants' meat and dairy eating patterns. The conclusion to this chapter provides a list of the general findings of the interview results.

\subsection{Overview of the drivers}

Four main drivers were discussed with the participants, giving them the option to choose from one to two drivers that they identified with regarding their meat and dairy consumption 
attitudes. The domain-specific values included 1) faith-based and 2) health-based, and the ethics-based drivers included 1) environmental ethics and 2) animal welfare.

Within the domain-specific values drivers, six of the participants mentioned faith-based attitudes as a driver of meat and dairy consumption attitudes, and six mentioned health-based attitudes as a driver. As for ethics-based drivers, nine participants spoke about animal welfare as the driver of their meat and dairy consumption, and 10 mentioned environmental ethics. One of them was unable to identify with any of the drivers; even though he initially appeared to be associated with the environmental ethics driver, he was still learning about his attitudes around meat and dairy consumption, and considering a change in his own behaviour, which was why he was interested in contributing to this research. However, he did speak about his culture and personal relationships as a driver of his current attitudes toward meat and dairy consumption.

A fundamental question I asked every interviewee was, 'What ethics- and value-based drivers do you perceive to influence your meat and dairy consumption?'. One interviewee explained that environmental ethics was the main factor influencing her attitudes towards meat and dairy consumption, though there were others:

I think my primary reason was for the environment when I learnt what kind of impact animal products have on the environment, and that was what generated my interest. As I have learnt more about it, there were more reasons for me, and the main reason for me was an ethical one. (Paige, 27, female, Pākehā 24 February 2020)

Another interviewee with similar drivers to Paige said in response to the question: Health and environment. Probably environmental first then health second, but for those reasons. (Mark, 60, male, Pākehā, 3 February 2020) 


\subsection{Interview findings for domain-specific value drivers}

\subsubsection{Faith-based values influencing people's attitudes}

Six of the 13 interviewees indicated that they have a faith-based value as either a direct or indirect influence on their attitude towards meat and dairy consumption. The faiths mentioned were Christianity—including Māori-Christianity (Ringatu, noted by one Māori participant as his religion, is influenced by Christianity and Māori beliefs)—Buddhism and Islam.

As explained in Chapter 2, I chose to categorise secularism as a faith-based attitude due to the influence secularism has on someone's faith. Two of the six interviewees had secularism as an influence on their meat and dairy consumption. One of these two practised vipassana meditations which played a role in defining her choice of diet. Below is how the participant described it:

... vipassana meditation course, it's a ten-day meditation course. It's an old form of meditation, and it's supposed to help you see reality as it is. I feel like we are taught to see things a certain way like our culture and experiences. Meditation, for me, is more about seeing things how they are and not through how you have been brought to see them. So that happened to me regarding animals; we were taught not to see animals as pets or food. But the difference is this arbitrary cultural view that has been imposed, and if we take that off there is no real difference between those animals, and to me, that was a big moment to see through that arbitrary distinction. (Paige, 27, female, Pākehā, 3 February 2020)

\footnotetext{
8 Vipassana meditation: a form of self-exploratory meditation technique rooted in Buddhism that is focused on a deep interconnection between the mind and the body, usually achieved through close attention to physical sensation.
} 
Conversely, one of the participants who identified himself as a Muslim stated his driver to consume meat and dairy was purely religious, he said:

If my religion tells me that I can eat meat, then I can do so. (Anwar, 33, male,

Bangladeshi, 21 February 2020)

Anwar was referring to types of meat permissible to be consumed in Islam. For example, the consumption of pig meat and its derivatives is forbidden in Islam. I asked him: 'How does Islam perceive the environment?'. This is how he expressed it:

I think Islam is a balanced religion, and if you look at the meat permissible for us to eat, most of these animals eat grass. So animals that eat grass are halal. (Anwar, 33, male, Bangladeshi, 21 February 2020)

Anwar explained his interpretation of why Islam only allows certain types of meat, which to him justifies his meat and dairy consumption and forms his attitudes.

On the other hand, Simon identified himself as a practising Buddhist, spoke about the impact his religious views had on his attitude around meat and dairy consumption. He stated:

Saint Paul says that we should kill and eat, and there are other references in the Old Testament as well ... there is nothing wrong with being a vegan and a Christian and dominion over the animals of the Earth doesn't mean you should eat them. I think it says that man has the responsibility to look after animals.

(Simon, 42, male, British, 5 February 2020)

The quotations above both demonstrate a faith-based value driver when it comes to meat and dairy consumption. For instance, Simon was following a vegan diet, but had a particular understanding of what the Bible says in relation to animal slaughter as his way to demonstrate that one can change their meat and dairy consumption behaviour while practising their religion or faith. Moreover, his religious belief played a part in his meat and dairy consumption attitudes: 
I became a vegetarian first for a lot of reasons. I guess it was part of the journey, as well as discovering that I didn't need to eat meat, milk or eggs. And that is when I became a Buddhist 11 years ago. (Simon, 42, male, British, 5 February 2020)

Simon's attitudes towards his meat and dairy consumption led to his faith-based values. His conversion to Buddhism led in turn to his decision to abstain entirely from consuming food of animal origin.

One of the interviewees, whose choices were influenced by his relationships - in this case, his wife - chose to change how often he consumed types of meat after his marriage. He explained:

The reason why I eat what I eat today is that I have respect towards religious practices, and what my wife chooses to eat. (Tere, male, 43, Māori, 13 February 2020)

Tere's wife, who is a Buddhist, followed a strict regime about the family's meat and dairy consumption. However, this did not erase Tere's personal consumption attitudes: he related that he hunts and slaughters animals when he has the opportunity, and his mother would provide him with meat from the family farm. He stated that his faith-based values and health influenced his attitudes towards his meat and dairy consumption. He expressed the relationship between his religious practices and ethics, stating:

Being a Māori-Christian, Ringatū, a religion in New Zealand, teaches how to bring your food, and it's our old way of hunting and fishing. Māori beliefs have ways of getting our food ... We pray to the deity that was wherever we go to or to the deity that provided our sustenance. Once Christianity was translated [to Māori] it became easier to fit it in our tribal beliefs (Ringatū) So, for us, there is a link here. I still say my prayers before we go hunting or fishing just to keep 
ourselves safe. That's where the Holy Trinity comes to place, and the Holy Spirit is with you. That's how my father taught me Māori customs. We thank the sea or the bush or the forest for what we were given. We usually leave an offering, whether it being a piece of the meat or putting back our first fish we catch to the water, even if the first catch was a big fish. (Tere, male, 43, Māori, 13 February 2020)

One thing that stood out in the interview was how Tere sourced his meat and dairy products; for example, he preferred meat from local farms rather than the supermarket. He explained:

Yes, it must be local, we usually go to the farmers market to get our meats. Mainly from Masterton. My wife often does that as she emphasises the importance of chicken and eggs to be farm-raised. I don't buy chicken and fish from the supermarket. This helps support local farmers. And I can tell that the meat tastes better compared to meat you get from the supermarket ... We also care about the way the animal is slaughtered. (Tere, male, 43, Māori, 13 February 2020)

Tere's current attitudes around his meat and dairy consumption originated from the Māori teachings his father ingrained in him, which led him to make these conscious choices.

\subsubsection{Health-based values influencing people's attitudes}

For six of the 13 interviewees, their attitude towards the consumption of meat and dairy was influenced by health-based values that primarily focus on maintaining personal health. Three of those six interviewees were vegan. The other three were 'flexitarians'; to them, they were simply reducing meat and dairy consumption to maintain a healthy body. All six individuals had chosen to eat a more plant-based diet after being originally raised and then 
following a diet consisting of mainly meat and dairy. For example, one event in Tere's life led to him reducing milk consumption:

As for dairy, I limit my milk consumption due to health reasons, [I] found that [milk] gave me stomach issues. Instead, I have almond milk now. But I do have milk or cream with my cereal ... [It started] in 2016, where I began the 'Whole Life Challenge' with my gym. I cut out milk and sugar for that month of the challenge. So in that process, I found that when I consumed milk again, I would get stomach issues ... that's when I phased myself off milk, mainly for my health. (Tere, male, 43, Māori, 13 February 2020)

Tere had a clear idea of what milk does to his health, which is why he decided to limit his consumption of dairy. The same thing happened with his meat consumption: after getting married, his meat consumption lessened, and he noticed a difference in his health overall. He described it like this:

When I was growing up, we had a lot of meats and potatoes, and a bit of greens. When I married my wife, eating vegetables was increased ... I was brought up in a traditional New Zealand farming lifestyle, where meat and potatoes were a staple for us ... but when I came out and met the world, and met other people, things changed, more veggies have been introduced. It took me a while to accept the new lifestyle, but to be honest, I'm feeling much better, especially after cutting out dairy. (Tere, male, 43, Māori, 13 February 2020)

For Simon, one of the factors in abstaining from dairy products was his son, who is allergic to dairy:

I guess it was a whole lot of reasons why I became vegan, and my son was allergic to cow's milk ... I think it was part of the journey as well. (Simon, 42, male, British, 5 February 2020) 
With his son's health issues, it was better for Simon to follow a dietary regime that would suit all members of the family.

Another of the six had experienced breast cancer and opted to be a vegan to avoid the risks, in her view, that come with meat and dairy consumption. She expressed that hormones found in milk were not only a significant cause of breast cancer but made any existing breast cancer worse.

So now my reasons are for health and the environment. And maybe a little bit for the animals. But when I first became vegan, it was because of my health, because I'd had breast cancer. (Sarah, 65, female, Pākehā, 18 February 2020)

Carla's health-based values influencing her diet came about after she had complained of low blood pressure and generally becoming sick often. She also decided to follow a vegan diet for a while to help in the treatment of breast cancer. She related:

So from the breast cancer perspective. I take one pill a day, and it's called Tamoxifen. And Tamoxifen, what it does is it prevents the [animal] hormone from entering my body. So, I think many people are not aware of what Tamoxifen is doing because they just keep eating meat and dairy. But they are relying on the Tamoxifen to block the hormones from the meat and dairy. (Carla, 52, female, Māori-Pākehā, 10 February 2020)

This relates to Carla's experience with her breast cancer medication. She explained her understanding of Tamoxifen's properties and how it affects the human body. 


\subsection{Interview findings for ethics-based drivers}

\subsubsection{Environmental ethics influencing people's attitudes}

This group was the largest, with 10 of the 13 of the interviewed population mentioning environmental ethics as a driver of their meat and dairy consumption. Drivers included measures to reduce plastic waste and the avoidance of air and car travel to minimise air pollution and carbon emissions.

One of the common questions I asked my interviewees was: 'How do you perceive the environmental implications of meat and dairy consumption?'. Omar, who moved to Wellington (and New Zealand) a couple of years ago with his wife said:

It's only because of my career background [as an environmental engineer] that I know the dairy and meat industry, they take up a lot of resources and waste, and that is a big problem to treat. If it were not appropriately treated, pollution would become worse, and waterways in New Zealand will be destroyed, disrupting the ecosystem. That's why we should be conservative around the dairy industry to be specific, putting in some control, starting with the use of technology to control the output of this industry that is creating havoc to the environment [around the world]. Perhaps New Zealand is not severely impacted, but human impact is getting worse. (Omar, 34, male, Egyptian, 3 March 2020)

Omar did not follow a specific diet; however, he was conscious of his meat and dairy consumption. Upon his arrival in New Zealand, his choices were altered from his home country's culture. This is how he described it:

[I noticed] from visiting Arabian countries, they consume a lot of meat. Especially during a celebration or a big occasion ... A big chunk of the meat goes to waste as the consumption is not wise, which makes it worse ... Upon arriving in New Zealand, my meat consumption became slightly more. This is because I cannot 
find ingredients for recipes we used to make in my home country. Substituting with meat was easy since it was available everywhere. I used to eat more vegetables, beans and rice. (Omar, 34, male, Egyptian, 3 March 2020)

Omar spoke about how his Egyptian culture is not highly focused on meat consumption, with beans a staple in the Egyptian diet. He found it difficult to mimic his home country recipes in New Zealand. Omar described people's drivers of dairy consumption as egocentric:

I think most incentive for people would be for their health rather than the environment. Because of how egocentric people can be, their choices will most probably be around their health rather than environmental protection. Of course, both drivers are essential, but it is more important to think about the environment. (Omar, 34, male, Egyptian, 3 March 2020)

If an individual's health is normal and healthy, their focus shifts towards other things, and it makes it easier for them to make conscious choices around their meat and dairy consumption. If wellbeing is disrupted, it is unlikely an individual would prioritise something else other than their health and happiness.

Conversely, Simon's response to the above question about his perception of the environmental implications of meat and dairy consumption was as follows:

I'm a strong environmentalist. I try to reduce plastic waste. I don't drive a car. I try not to fly. I'm trying to get to Australia in October. I'm looking at ways of getting to Australia carbon-free. I think we should all be looking at that. (Simon, 42, male, British, 5 February 2020)

Anwar had a differing view of meat and dairy consumption, favourably pointing out that if animals were not slaughtered, they would increase in population and over-utilise resources such as grass, resulting in them lacking enough feed and starving to death. He described it as follows: 
If you consider my country, the farmers are relatively poor. They don't have much to eat. What else would they eat? ... if you keep an animal, you will see that it will grow in numbers, then there won't be much space for humans to live ... the number of human populations is increasing. So grassland and forests are decreasing. These animals will not survive due to that, and animals will be killing each other, which will disrupt the balance. That's why we must slaughter animals. This balance is good for the environment as well as for humans. (Anwar, 33, male, Bangladeshi, 21 February 2020)

Anwar's justification seemed at odds with what has been covered in this study's literature review. He referred to the overpopulation of animals around the world and the importance of slaughtering them so the balance between the human population and animals is maintained. However, not much evidence is available to support the idea that slaughtering farm animals would support environmental efforts.

Mark spoke about the issue of meat consumption from a different perspective to Anwar. He says:

When you look at greenhouse gas emissions and that kind of thing globally, meat is worse. But dairy for New Zealand, most of the bulk of the meat eaten in this country comes from dairy cows. So they are not two separate things. So every dairy cow gets replaced about every three years on average. So most of the meat that you are eating in the supermarkets are dairy beef. (Mark, 60, male, Pākehā, 3 February 2020)

A similar perspective was shared by Belle, who had lived in New Zealand most of her life. She had taken a step to research environmental ethics concerning meat and dairy, to understand what her stance is within society. She described it as follows: 
It comes down to a very important piece of research related to water use that I read quite a while ago. I think the values of appreciating something and valuing it is important to me. And that is how I see it because when I saw how much water beef [production] takes, including the production of grains and whatever, I realised that, why do we need to eat it, and then so much [of it] is wasted? So knowing that a thousand litres are needed to make one kilogram of beef versus chicken or fish, whether it's 50 or 60 [litres], I can't remember now. (Belle, 53, female, Chinese, 13 February 2020)

Belle educating herself about the impact of her meat and dairy consumption is apparent in the above quotation. The comparison she made between the requirements of red meat production versus that of chicken and fish led her to question why red meat production requires a huge amount of resources, in turn, leading to her current attitudes around her meat and dairy consumption drivers.

\subsubsection{Animal welfare influencing people's attitudes}

Nine of the 13 interviewees considered animal welfare a factor when deciding whether to consume meat or dairy products. Most of the participants who identified animal welfare as an influence refrained from the consumption of meat and dairy for environmental reasons as well, whereas six of those nine had it as their second reason for deciding not to consume meat and dairy. For example, Mark refrained from meat consumption for 20 years; however, as I observed during the interview, he did not mind adding milk to his coffee from time to time. He explained it in this way:

I eat dairy, not meat. And minimal dairy ... in my coffee, that's all ... I haven't eaten meat for 20 years, and when I stopped eating meat, it was for animal welfare and maybe health. And then I felt so much better. But then my awareness of the 
environment came later. I wasn't as aware back then as I am now. (Mark, 60, male, Pākehā, 3 February 2020)

As Mark explained, animal welfare played a big role in him altering his meat and dairy consumption habits.

The remaining three opted not to consume dairy and meat primarily based on the view that it was a violation of animal rights. Darwin, who was expressive about his reasons for not consuming meat and dairy, said:

I don't agree with using animals for anything ... So I had given up dairy for about nearly two years. Before that, I was just eating fish, no dairy, no other meat. Simply fish and eggs. My wife's been vegan for several years. She was vegetarian when I met her, and I ate meat and cheese and eggs and was just a regular carnivore. (Darwin, 42, male, British, 10 February 2020)

Originally from Britain, Darwin moved to New Zealand in 2007. His wife, who followed a plant-based diet, did not influence his attitudes towards his meat and dairy consumption habits before his switch in June 2019. He began his journey of shifting his consumption attitudes in 2017 when he started cutting out dairy products. As noted above, Darwin described himself before that period as a 'carnivore', one that eats meat, whereas a herbivore refer to one that consumes plants. These two definitions are mainly used by plantbased and vegan individuals to distinguish their attitudes around the consumption of, or abstinence towards, animal-based food. Darwin viewed dairy and meat consumption as an act of humans making use of animals. He expressed it as:

It's hard to be compassionate for all living beings if you're eating them and taking their stuff ... I feel guilty that I'm not out helping animals and saving them and doing more. I think the bare minimum we could be doing is not farming them for our pleasure. (Darwin, 42, male, British, 10 February 2020) 


\subsection{Crossovers between values and ethics views}

A crossover refers to the occurrence of a connection between more than one driver, specifically one domain-specific value with one ethics-based driver that the participant could not separate when explaining their attitudes towards their meat and dairy consumption. Several crossovers were identified during the interview process and through coding and analysis. Some of the crossovers were pointed out directly by the interviewees; for instance, a crossover of faith-based values and animal welfare was, in all cases in which it applied, mentioned directly by the interviewees. When I began the research, I assumed that individuals would find or choose one specific driver that influenced their meat and dairy consumption. However, the crossovers were vast; some interviewees had more than two drivers that influenced their meat and dairy consumption attitudes. This research will focus on the most significant crossovers that occurred between two drivers. Below is a list of the most noteworthy ones:

1. Health-based values - environmental ethics crossover

2. Faith-based values - environmental ethics crossover

3. Faith-based values - animal welfare crossover 


\subsubsection{Health-based values_environmental ethics crossover}

The reoccurring crossover between health-based values and environmental ethics was apparent and strong across the journey of my interviews. Nine interviewees spoke about it explicitly. Upon asking one of my interviewees about what driver defines their meat and dairy consumption, Mark said:

My choices are health and environmental, probably environmental first and health second. But for both those reasons. (Mark, 60, male, Pākehā, 3 February 2020)

Another similar example was Paige, who said:

I want to stop causing harm to any other being, have less impact on the environment and, for my health. When I started learning more about it, I realised I didn't want to consume more animals. (Paige, 27, female, Pākehā, 24 February 2020)

Correspondingly, Sarah expressed a crossover between health and environmental ethics as equally-important drivers to her meat and dairy consumption attitudes. She described it as follows:

It's equal with environment because that to me now is just becoming more and more important ... So now my reasons are for health and for the environment, and maybe a little bit for the animals. But when I first became vegan it was because of my health because I'd had breast cancer. (Sarah, 65, female, Pākehā, 18 February 2020)

One of the participants explained his reasoning regarding why health-based and environmental ethics drivers go together. Anwar spoke about his environmental perspective and why it is difficult to separate an individual's health from the environment: 
From an environmental perspective. I investigate my health; it's ultimately going to get affected by the environment. If you are concerned about your health, that means you are concerned about the environment. For example, if one was concerned about air pollution coming from car fumes, it will impact my health negatively, and therefore, it is not good for the environment as well. (Anwar, 33, male, Bangladeshi, 21 February 2020)

Although the participants come from different ethnicities, ages and genders, their agreement on the integral relationship between human health and environmental ethics is clear, as seen in the above quotations.

\subsubsection{Faith based values-environmental ethics crossover}

Three of the 13 interviewees pointed out that both environmental ethics and faith-based values influenced their meat and dairy consumption. According to them, their faith showed concern about how the environment was to be conserved and encouraged one not to consume blindly. Here is an example of how Simon explained it:

In Buddhism, we look at things as cause and effect... So it's sort of a little bit of all [drivers]. Because I eventually became vegetarian ... it's obviously tied to my religious belief ... I'm also a strong environmentalist. I try to reduce plastic waste.

I don't drive a car. I try not to fly. (Simon, 42, male, British, 5 February 2020)

Another example of this crossover comes from Anwar, who spoke about the relationship between his religious belief and environmental ethics:

As for the animals, I think that Islam is a balanced religion ... Islam says many beautiful things, and for example, Prophet Mohamed (P.B.U.H9) said you are not 
allowed to cut trees just for no purpose unless it is necessary, or cut trees during a war ... Islam does not agree with the destruction of the environment. I think Islam is environmentally-friendly. (Anwar, 33, male, Bangladeshi, 21 February 2020)

\subsubsection{Faith-based values_-animal welfare crossover}

Four interviewees attributed their attitude towards meat and dairy consumption to both faith-based values and animal welfare. According to the interviewees who were vegan or vegetarian, their faith required one to have a concern for the well-being of animals and humans equally. For those who were consumers of meat and dairy, their views stemmed from their religion; that is, their faith had criteria that showed that while consuming meat or dairy products they observed animal welfare to some extent.

\subsection{Other interview findings}

While conducting the interviews, further influences on participants' attitudes around their meat and dairy consumption emerged. Below are some other emerging meat and dairy consumption drivers that I found to be interesting. Six interviewees spoke about their culture being a driver, and eight of them said that their meat and dairy consumption attitudes were influenced by their relationships (e.g., friends and spouses).

\subsubsection{Cultural drivers on influencing people's attitudes}

Six of the interviewees noted culture as one of the influencing drivers on their attitude towards meat and dairy consumption, and Warren had culture as his sole influence. Some interviewees were from different cultural backgrounds, and some had come to New Zealand from different countries. Some of the different nationalities included Malaysian, Hungarian, Kuwaiti, Bangladeshi and Egyptian. Here is an example from the interview with Anwar: 
In my country, we don't slaughter a cow that is already giving milk. But once it stops giving milk, and stops feeding her baby cow, we find that the best option is to kill it and harness the money, spend it on some other food, nutrition and education. This is like a cycle. (Anwar, 33, male, Bangladeshi, 21 February 2020) In this part of the conversation with Anwar, he explained how his meat and dairy consumption attitudes are driven by what is available and optimum in his home country. It also provided a glimpse of the relationship people in India have with their cows. For example, the importance of allowing the cow to feed her calf before deciding to slaughter her for food.

Conversely, Omar mentioned that the cultural influence on his meat and dairy consumption was ingrained. He says:

I have never thought about my incentive to eat meat or chicken or just vegetables. It's something cultural, you just grow up and you eat meat and you eat chicken and you eat dairy ... yeah, it's part of our culture we don't think and worry about what we eat too much. (Omar, 34, male, Egyptian, 3 March 2020)

Five of the 13 interviewed individuals had moved from their home country to a new environment in New Zealand. This had influenced, to some extent, their attitude towards the food they ate. Of the five, none had changed attitudes towards meat and dairy consumption solely because of environmental change; for the interviewees for which this played some role, the need to adapt to a new environment was a secondary factor beneath drivers such as health or influence from relationships. Some said they found it challenging to stick to their original choice of food because it was not abundantly available in their new environment, thus prompting them to adapt to the locally-available diet. As Zak illustrated:

When I left Hungary, I would consider it was difficult to find or choose vegan or vegetarian options because the culture is kind of an 'eating meat' culture for eating, more milk products. I lived in Ireland. In Ireland, also like New Zealand, 
they have a very strong agriculture environment. The milk products and the quality of milk in Ireland are quite similar. They are considered as a top-quality. (Zak, 44, male, Hungarian, 10 February 2020)

Another example of how culture played a role in influencing an individuals' driver to their meat and dairy consumption was from Warren:

After moving to Wellington, and just of late, I'm in a new environment now. I've changed the people around me. Before this, I was living with my mother. And before that, I've always lived with my family. And I think it's a combination of that, and not having people around me that were interested in this way of thinking. (Warren, 24, male, Māori, 21 February 2020)

Warren used to consume meat and dairy while living with his family, but after moving to Wellington from Napier, his views around meat and dairy consumption changed. The absence of normalised attitudes exposed him to different drivers. He identified his meat and dairy consumption drivers to culture and convenience:

Reasons why I chose to consume meat and dairy is convenience. Maybe not even that, because I guess it's just normal, right? (Warren, 24, male, Māori, 21 February 2020)

\subsubsection{Relationship drivers on influencing people's attitudes}

Eight interviewees identified their relationships as influencing their attitudes towards meat and dairy consumption. Relationship drivers are identified when an individual's attitude towards meat and dairy consumption is influenced by someone other than the individual; in this case, it refers to friends and family, both those related to someone by marriage or by blood such as someone's parents and siblings. For example, Simon says: 
I originally became vegetarian, and that was primarily because my wife was a vegetarian. (Simon, 42, male, British, 5 February 2020)

Although Simon's driver at the time of the interview towards his meat and dairy consumption attitudes was faith-based, the role his wife played in shaping his current values were important. Moreover, he attributed his previous meat consumption to family influence:

Family influence. As a child, as many people, we were told that we had to eat meat. (Simon, 42, male, British, 5 February 2020)

A similar example comes from Adil's interview:

Sometimes when I visit my family members, they would serve meat or chicken on the table. As you know, Arabs are always keen on feeding you! And meat is an important component on the table; if you don't serve meat to your visitors, you would look like a scrooge. (Adil, 51, male, Kuwaiti, 3 March 2020)

The above example from Adil's interview illustrates both the relationship and cultural drivers towards meat and dairy consumption attitudes, emphasising the position he was put in when visiting family members. Arabs are generally known for their generosity, and if Adil were to refuse his family's generosity, he would be considered impolite.

Another example that illustrates how an individual's attitudes are influenced by relationships came from Warren's interview. He noted that his girlfriend was not keen on the idea of reducing meat consumption. Here is how he explained it:

My missus, she was not happy about it [when Ifloated the idea] ... I haven't really addressed my feelings to her about it or thoughts on the information I've been exposed to, So I think I'm in a period of absorbing new information. (Warren, 24, male, Māori, 21 February 2020)

This led Warren to explore his meat and dairy consumption further. He began learning from sources such as documentaries focusing on animal welfare and environmental protection: 
Watching [documentaries] like that is something that I never paid any mind to before. And no one around me paid any mind to it as well, and it made me reflect a little bit ... I haven't really addressed my feelings. But I can say, I don't particularly want to eat meat. Yeah, so I'll mention it to my girlfriend [again], that maybe I want to stop eating meat. (Warren, 24, male, Māori, 21 February 2020)

Warren's exposure to certain types of information influenced his attitudes around meat and dairy, whereas his girlfriend was not very happy with the shift in attitudes. This shows the influence of relationships on Warren's attitudes around meat and dairy consumption.

\subsection{Results summary}

Prior to starting the interviewing process, my thought was that the information would focus on unique domain-specific value drivers or ethics-based drivers. However, the subject matter was incredibly complex. Below is a list of the findings:

- Important life events play an essential role in shaping an individual's attitude around meat and dairy consumption.

- Most of the participants interviewed were aware of the environmental impact of specifically-meat and dairy consumption, including participants who attributed their behaviour around meat and dairy consumption to domain-specific value drivers.

- Analysing the complexity of the participants' drivers towards their meat and dairy consumption attitudes allowed me to understand that each individual has a complex behavioural pattern, influenced by different factors. 
- The themes discussed during the interviews had some important crossovers. For example, some interviewees could not separate the link between their religious beliefs and environmental ethics.

- Interviewees of non-New Zealand origins had entirely different attitudes towards their meat and dairy consumption preferences. For example, an interviewee of Middle Eastern origin believed it is important to consume meat and dairy to maintain human dominance over other species.

- Interviewees of Māori origin had strong beliefs towards the attitudes behind their meat and dairy consumption and their relationship to the environment (e.g., Kaitiakitanga, which is expressed today as environmental renewal and guardianship). Interviewees of Pākehā origin had similar views, but with more secular views that drive their meat and dairy consumption.

My interviews aimed to gather the information required to guide me in answering my research questions. During that process, I realised that an individual's drivers towards their meat and dairy consumption stem from a much more complex structure than simply one or two drivers. Moreover, the fact that humans are multifaceted makes their journey towards their consumption behaviours more rewarding and exciting to learn about. 


\section{Chapter 5: Discussion—exploring attitudes}

\section{The highest form of human excellence is to question oneself and others.}

Socrates, 469-399 BC

This chapter draws findings from participants' interview quotations to discuss views around domain-specific and ethics-based drivers on meat and dairy consumption attitudes. Socrates' quote above summarises the reasoning behind why it is important to question and discuss different opinions in order to excel in our behaviour. The discussion chapter demonstrates how findings from this research relate to current literature on people's attitudes towards meat and dairy consumption. Then, the chapter underlines the environmental mitigation opportunities through a change in consumer attitudes. Finally, this chapter discusses the research limitations, strengths and weaknesses, and suggestions for future studies.

The following research questions are discussed:

- What ethics- and value-based drivers are perceived by some people in society to influence their meat and dairy consumption?

- How do interviewees perceive the environmental implications of meat and dairy consumption?

- How can findings from the research inform behavioural change?

\subsection{Domain-specific views}

Following Oppedijk van veen and Verhallen (1986), domain-specific values are a group of beliefs that shape the behaviour of certain domain activities. In the present research, the explored domains were faith-based and health-based. Chapter 2 discussed why these two domains were chosen. 


\subsubsection{Faith-based attitudes}

The results of faith-based attitudes indicate that six of the participants identified faithbased values as their main driver of their attitudes towards meat and dairy consumption. These results confirm earlier research by Azam (2016), who found that religion influences food choices according to their faith. His research noted, however, that religious people, to a great extent, are not fully aware of the impact of food choices on the environment. Furthermore, by not giving specific guidance on environmental conservation, some religious interpretations leave it open to the believer to approach life so long as a balance is achieved. Anwar expressed it as follows:

Islam is like a balance. It will not tell Muslims to destroy the environment or it will not say keep the plants and trees growing or don't touch them. So you need to be in the middle side, and you need to make a balance. So that's what Islam prefers, and I think that Islam is quite environmentally friendly. (Anwar, 33, male, Bangladeshi, 21 February 2020)

The point Anwar is referring to is from the teachings of Islam that although it is important to care for the environment and trees, there is no harm is cutting some of them for the benefits of humanity. This attitude leaves it open to the believer's choice, unless another element, such as a health factor, takes priority. As mentioned in Chapter 2, a study by Hope et al. (2014) explained that religious participants had more relaxed attitudes with regard to reduced consumerism and pro-environmental action than their secular counterparts.

Some religious beliefs validate the consumption of meat and dairy so long as it is prepared in a certain way. Anwar expressed his consumption of meat as something his religion permits him to do, so long the meat was slaughtered following the halal slaughter method. However, current practices show noticeable variation and degree of strictness on certain rules extracted from religious texts. For example, the method of animal slaughter described in Islamic 
teachings state which food is halal (permissible) and which is haram (forbidden). As written in the Qur'an, the holy book of the Islamic faith, Allah (God) says:

Prohibited to you are the dead animals, blood, the flesh of swine, and that which has been dedicated to other than Allah, and killed by strangling or by a violent blow or by a head-long fall or by the goring of horns, and those from which a wild animal has eaten, except what you [are able to] slaughter, and those which are sacrificed on stone alters, and [prohibited is] that you seek decision through divining arrows. That is great disobedience. This day those who disbelieve have despaired of your religion; so, fear them not, but fear Me. This day I have perfected for you your religion and completed My favour upon you and have approved for you Islam as a religion. But whoever is forced by severe hunger with no inclination to sin - then indeed, Allah is Forgiving and Merciful (Qur'an 5:3) A similar religious practice to Islam's method of permissible slaughter is Jewish kosher slaughter (shechita). In the Torah, it says:

If the place which the LORD thy God shall choose to put His name there be too far from thee, then thou shalt kill of thy herd and of thy flock, which the LORD hath given thee, as I have commanded thee, and thou shalt eat within thy gates, after all the desire of thy soul. Deuteronomy 12:21

The Jewish slaughter tradition has certain procedures that are forbidden to apply when slaughtering a mammal. For example, the technique of shehiyah (pausing), derasah (chopping) and hagramah (cutting in the wrong location) are some of the practices that are forbidden when performing shechita (Jewish kosher slaughter). Islamic and Jewish teachings both prohibit the consumption of pork, and require certain similar procedures to perform the proper slaughter method such as the slaughter of the mammal using a sharp blade. Lever and Fischer (2019) explained that the practices do differ in certain aspects of animal slaughter and the consumption 
of animal products. More species of animals are prohibited in kosher, such as shellfish, but in Islamic teachings it is halal to consume shellfish.

For Muslims, it is permissible to consume meat slaughtered by 'people of the scripture'-Jews and Christians - since it is part of the Islamic faith to believe that the Torah and the Gospels are holy books like the Qur'an, hence it is common to have similarities to the methods of slaughter and animal welfare between the holy books. The following verses from the Qur'an illustrate that:

Today, all good food is made lawful for you. The food of the people of the scripture is lawful for you, [and your food is lawful for them] Qur'an 5:5

You shall eat from that upon which God's name has been pronounced, if you truly believe in His revelations. Why should you not eat from that upon which God's name has been mentioned? He has detailed for you what is prohibited for you, unless you are forced. Indeed, many people mislead others with their personal opinions, without knowledge. Your Lord is fully aware of the transgressors. Qur'an 6:118-119

In a study conducted by Mohamed (2011) on the complementary effect of halal principles and sustainable concepts, it was found that practising religious consumers have expressed more awareness about halal principles in relation to sustainable concepts and the production process. The demand for halal products has increased; currently New Zealand exports 90 per cent of its red meat products within halal export-approved guidelines (Lloyd, 2012). To meet demand, halal slaughterhouses focus on the quickest application of the slaughter method, which is simply running a sharp knife across the neck of the mammal, without considering the remaining requirements for halal produce such as ensuring animal welfare and the prohibition of stunning, which is forbidden according to Islamic teachings. Practices differ around the world, but the Islamic teachings are often ignored; in the UK between 84 per cent 
and 90 per cent of animals slaughtered for halal meat are stunned before slaughter (Mobayed et al., 2016).

Other religions mentioned by interviewees as forming faith-based attitudes included Buddhism, Christianity, Māori belief (as expressed in karakia, ritual chants or prayers), and secularism. Interviewees who identified themselves as Buddhists were practising veganism, despite them noting that Buddhism does not restrict or specify the kind of food one consumes and gives freedom to the believer to make their own choice on whether to consume meat and dairy. Simon explained it as follows:

So I think the same exists within Buddhism. There are many Buddhists that do eat meat or drink milk. Buddhism isn't a dogmatic religion, so it doesn't have a set of rules. It has a set of explanations and encourages you to think around pretty much everything; you should always think about everything. (Simon, 42, male, British, 5 February 2020)

According to Simon, Buddhism, in general, leaves open the choice of what to eat and what to leave. However, in Buddhism, different schools have different rules concerning diet. For instance, Mahayana restricts eating any kind of meat, while the Vajrayana schools allow the consumption of meat as well as other products such as alcohol. It is common for Mahayana Buddhism to be practised in East Asia, and the nuns there follow a strict vegan diet (Ho-Pham et al., 2009). Moreover, Ho-Pham et al. (2009) explained that vegetarianism is increasingly popular in Western countries. Therefore, certain Buddhist people like Simon prefer to follow this sect of Buddhism, as it complements their attitudes around meat and dairy consumption.

In Christianity, meat and dairy consumption is allowed. However, during certain days, such as Good Friday — when Christians commemorate the crucifixion of Jesus Christ—certain groups of Christians, for example, Roman Catholics, do not consume meat. Tere, who identifies himself as a Christian-Māori, believes that animals are created to co-exist with humans: 
I don't accept mistreating animals. An animal needs to have a good life and let it live it to the best, so then you get to enjoy consuming it the right way. I go hunting with my boys. I am quite scared that my boys won't accept the way we slaughter animals ... because one of my boys was scared of the process once when I was about to kill a deer. But this is just the process of desensitisation. My boys don't mind catching fish and shellfish, though, but it's harder when it comes to mammals. (Tere, 45, male, Māori, 17 February 2020)

Unlike the religious, who believe in a supernatural being, people with identified secular views often have a strong focus on values concerning humankind — such as those behind philosophy and meditation - to achieve higher truths while trusting the human strength. One of the interviewees, who is secular, practised vipassana meditation. She pointed out that after starting to practise meditation, she began reflecting on her behaviours, leading her to question some things, such as what happens to an animal before it becomes a product:

... there is no real difference between those animals. To me, that was a big moment to see through that arbitrary distinction. (Paige, 27, female, Pākehā, 24 February 2020)

Karakia is a Māori practice to invoke spiritual guidance and protection. The interviewee who mentioned karakia also consumed meat and dairy, as his Christian-Māori religion allows it. These results build on existing evidence by Fuccillo et al. (2016) that religiously-prescribed traditions influence dietary habits. Belle, who has lived most of her life in a Māori neighbourhood, spoke about karakia as a practice followed for many years in her life:

I suppose, less-researched evidence about the whole thing of your disconnection from food is about poor health. Your health decline happens with this disconnection from your food and mindful eating. I believe that, but also to me it seems to make a lot of sense too, doesn't it? Mindful eating, being aware of - that's 
where the whole thing of karakia is, for blessing the food. we always say the karakia, bless and thank you Mother Earth. Thank you for the food, you know, we will eat it with love. (Belle, 53, female, Chinese, 13 February 2020)

Thus, faith is a significant pillar in determining a large percentage of the interviewees' attitudes towards meat and dairy consumption. The amount of the information and type of motivation given by different religious people, however, varied. In some cases, as seen above, interviewees adjusted religious practices to suit different diets and other facets such as culture.

\subsubsection{Health-based attitudes}

Some of the interviewees who identified their health as the basis for their meat and dairy consumption driver did so for different reasons. For example, Tere, who stopped consuming dairy, said:

As for dairy, I limit my milk consumption due to health reasons; I found that it gave me gas and a lot of problems in my stomach. I have almond milk instead now, but I do have milk with my cereal or cream with cereal. So I haven't completely cut it. (Tere, 43, Male, Māori, 13 February 2020)

He complained that whenever he consumed dairy, it gave him gastrointestinal issues; hence, he preferred almond milk. This could be considered self-reported lactose intolerance or maldigestion10. A study by Carroccio, Montalto, Cavera and Notarbatolo (1998) found that lactose maldigesters increased as subject age increased. This is due to the decreasing amount of the lactase enzyme as one ages, which leads to reduced consumption. Tere was 43 years of age at the time of the interview. He expressed that consuming dairy was not an issue before.

10 Lactose intolerance or maldigestion: an inability to digest significant amounts of lactose because of a genetically inadequate amount of the enzyme lactase (Swagerty, Walling \& Klein, 2002). 
One participant complained of low blood pressure and general body malaise, which led to seeking healthier practices in the vegan diet that she had initially followed for environmental and economic reasons. That vegan diet had come with some health-related issues, but those were fixed by introducing the limited consumption of some meat and dairy:

I think because I was working in a reasonably stressful job and I think that I was so tired all the time. I had low blood pressure, and with higher iron and that sort of stuff. And veganism didn't seem to work. And so, what happened is I started having a little bit of chicken, a bit of protein and that kind of thing. So I did actually almost notice the difference, after a while. And so I thought, well, if it was going to kind of balance it up, I will eat a bit. And it changed my life quite a lot actually. (Belle, 53, female, Chinese, 13 February 2020)

Belle had been following a vegetarian/vegan diet early on in her life when the practice of veganism was not widely known, and scientific studies were limited. However, she found that having what she saw a proper balance in consuming meat and dairy helped alleviate her health issues. As discussed in Chapter 2, Seves et al. (2017) found that replacing 30 per cent of meat and dairy with plant-based alternatives provides the human body with the average nutritional requirements.

Carla complained of the chronic diarrhoea that came with her consumption of dairy. Thus, she opted to moderate her amount of dairy intake:

I go through periods of eliminating both dairy and meat on a regular basis. Because I find that if I eat too much, I get too sick. So what I'm doing at the moment is I'm moderating quite heavily. So I will have one meal a day where I do have a meat-based protein, which will either be beef or lamb, chicken or fish. There is little dairy. If I want to get chronic diarrhoea, I'll go on a binge of cheese 
or sugar! My point is that both of them just make me very sick. It's just safer not

to have it. (Carla, 48, female, Māori-Pākehā, 5 February 2020)

A pattern can be identified from the interviewees' responses as to how a person switches their initial diet to a perceived healthier diet. All had switched after the age of 18 and after moving away from their family home, to whatever degree, and from the influence of parental food choices. Moreover, the independence of adulthood can also bring increased awareness of issues perhaps previously not considered. Further, as people age, health plays an increasing role in rethinking dietary habits. For instance, a widely-publicised study by Rozenberg et al. (2010) on the impact of dairy products on health showed that high consumption of dairy products increases the risk of cardiovascular disease. In general, participants who identified with the health-based attitude were moving from consuming meat and dairy to following a vegan or more plant-based diet. Many recent studies refute meat and dairy consumption as being healthy in which Friel et al. (2009) found the correlation between meat consumption and cardiovascular diseases. Moreover, research by Westhoek et al. (2014) highlighted that the Western diet is characterised by high consumption of meat, dairy products and eggs, causing an increase in saturated fat and red meat quantities that exceed dietary recommendations. The study examined diets with lower consumption of meat, dairy and eggs, and it was found that the protein intake was still at least 50 per cent higher than the dietary requirements recommended by the WHO (Westhoek et al., 2014). As shown in the above quotations of this subsection, the participants of this study reduced their meat and dairy consumption to improve their health. 


\subsection{Environmental ethics views}

In the present research, the explored ethics were environmental ethics and animal welfare. Chapter 2 discussed why these two ethics-based views were chosen.

\subsubsection{Environmental ethics attitudes}

The overall findings of this section, when compared, indicate this category to be the largest, with 10 out of the 13 participants stating that environmental ethics was one of the top concerns influencing their attitude towards meat and dairy consumption. Even if not an interviewee's primary driver, soon after mentioning any other themes behind their attitudes towards meat and dairy consumption, the interviewee would typically refer to environmental ethics in addition to the main factor. Among those whose attitudes were based on faith, their faith often required one to also tend to the environment. Those whose attitudes were based on health were concerned that if pollution from the meat or dairy industries affected water and the environment, then it would also affect other food sources such as plant foods. Lastly, those who had a concern for animal welfare referred to environmental ethics, as animals are dependent on the environment for survival. The responses show a high awareness among the interviewees of the impact of meat and dairy consumption on the environment in New Zealand.

The data collected from interviewing my participants confirm previous research published in the International Journal of Environmental Research and Public Health (SanchezSabate and Sabate, 2019). The findings showed that 50 per cent of Europeans were willing to replace most of the meat they ate with vegetables, and 80 per cent were ready to eat less meat. One of the interviewees expressed the great need for people to be aware of the impact that meat and dairy consumption has on the environment and especially the climate. This is in line with 
a finding by Deckers (2010), which revealed that increased awareness of moral veganism11 could help control the adverse effects of animal keeping on the environment. For example, Zak said:

I think it is easier to be vegan and follow this type of modern healthy lifestyle in New Zealand. When I was in Hungary, it was difficult to find organic shops that sell oats for breakfast in 2005. Even regular shops did not supply oats back then. Of course, this was not a problem for European culture, but for me, I read that eating oats was healthy for you. So I wanted to try that back then. (Zak, 44, male, Hungarian, 10 February 2020)

\subsubsection{Animal welfare}

The analysis indicates that three-quarters of the participants reported animal welfare as a driver behind their attitude towards meat and dairy consumption. Three of them reported animal welfare as the sole reason for being vegan because they disagreed with using animals as foods or pets. However, one of the nine interviewees indicated that animals for commercial use were increasing in population, and if this were not attended to, there would be overpopulation and over-utilisation of resources. From his perspective, slaughtering and consuming animals was one of the best measures to curb this problem and, thus, he regarded it as an animal welfare practice. One of the participants indicated that to counter the feelings of having to treat animals with the same respect as human beings, he had to learn how desensitise himself before slaughtering an animal for consumption. His view is in line with earlier research (Mark, 2013), claiming that animals are conscious beings and can feel pain. Thus, the ethical consideration 
applied to human beings should, with equal respect, also apply to animals. Below is an example from the interview with Tere:

I taught myself to get desensitised when it comes to the ethics around meat consumption and animal slaughter after eating my own pet pig without knowing and later on finding out I ate my own pet pig for Christmas when I was 11 years old. Having that detachment made it easier for me to slaughter my own animal for food. Having said that, I don't accept mistreating animals. An animal needs to have a good life, and let it live it to the best so then you get to enjoy consuming it the right way. (Tere, 43, Male, Māori, 13 February 2020)

Adil, who moved to New Zealand from Kuwait, talked about the ethics followed by New Zealand slaughterhouses. He worked as an animal slaughterer in the halal slaughter industry. He expressed the amount of care New Zealand regulation and practices have towards animals. Here is how he explained it:

The meat industry here, they genuinely care about the animals and following the procedures for trade. Thank God they are doing so. Slaughterhouses follow proper halal slaughter practices. Because it brings good money ... Compared to Arab countries, where most of it is a desert, it is not suitable for cows and sheep to live there. But, in New Zealand, the land is vast, and the animal can live a good life. You can tell how good New Zealand meat is by the taste of it. (Adil, 51, male, Kuwaiti, 3 March 2020)

Although most of my participants who eat a plant-based or a vegan diet would disagree with Adil's point above, the way animals are treated in New Zealand is more considerate towards animal welfare than other countries. New Zealand's current animal welfare legislation was introduced in the Cruelty to Animals Act in 1884, which led to the Animal Welfare Act 1999. One of the critical features of the act includes the obligation to care for animals. It 
establishes obligations for those responsible for the care of animals, including that they supply the animals with the opportunity to display normal patterns of behaviour, which is one of the internationally recognised 'five freedoms' of animals to display normal patterns of animal behaviour as one of the internationally-recognised 'five freedoms' for animals (MAF, 2009).

\subsection{Emerging drivers influencing meat and dairy consumption attitudes}

Certain drivers came up during the interviews that I did not choose to cover in the literature review of this research. This section highlights the most prominent drivers that came up frequently with my participants.

\subsubsection{Cultural drivers}

Five interviewees were immigrants from other countries. Further, three of the New Zealand-born interviewees had moved from a rural area to the city; they were raised on a farm and moved for reasons such as employment and education. Those who had moved from different countries found a different cuisine from the one they were used to, forcing them to adapt to a change in diet gradually. This, to some extent, affected their attitude towards the local food. Omar, who came from Egypt, expressed how different his dietary choices became upon arriving in New Zealand:

Upon arriving to New Zealand, I think meat consumption has been slightly more for me because most recipes that we do in our home country we cannot find here, so you have to substitute this with meat which is available everywhere. Back in my country, we have a lot of recipes with rice and vegetables. (Omar, 34, male, Egyptian, 3 March 2020) 
On the contrary, Zak has expressed that it was easier to consume less meat and dairy in Aotearoa New Zealand compared to his home country, but this is related to the nature of the culture in Hungary compared to Egypt. Zak described it in this way:

I think it's easier to be a vegan and be following this kind of modern healthy options when you are in a country which is actually open for this one. So, for example, comparing New Zealand with Europe, and of course, it's time difference also. Probably, as I heard that back in Europe also, I remember back in Hungary it was a problem whether we didn't or did have, there are really just some kind organic shops where I was able to buy for example just oat just for your breakfast meal. For example, like, buying oat, it was a difficult thing; when I have read about that oat is so healthy, I wanted to eat for breakfast just pure oat and porridge. And it was not easy. I remember it was in 2005 and it was difficult to find just oat in a regular shop. Of course, it was not a problem probably in a British culture, British shops like in UK, Ireland and New Zealand because it was always part of the breakfast routine. Yes, moving in other countries and you are like the kind of it's always on the shelf in the shop. So eating oat is easy. Meanwhile, I remember when I mentioned to my family that I eat or I prefer porridge in the morning if I have breakfast, they say 'We had to do this when you were younger' and it's considered when everybody was poor, they had only oat to eat. (Zak, 44, male, Hungarian, 10 February 2020)

It was expected by the participants that food and meal preparation habits would change after migration. As they expressed it, their attitudes towards their meat and dairy consumption changed too based on the new environment or culture they joined. A study by Holmboe-Ottesen and Wandel (2012) looked at changes in dietary habits after migration and consequences for health, and found that dietary changes depend on a variety of factors related to the person's 
country of origin, socio-economic and cultural factors and situation of the host country. Moreover, the study shows an increase in intake of meat and dairy foods, resulting in reduced vegetable intake (Holmboe-Ottesen and Wandel, 2012). The reason for an increase in meat and dairy consumption for immigrants was explained by Holmboe-Ottesen (2012) in which he categorises food in three main categories: 'staple foods' (carbohydrate-rich foods), 'complementary foods' (meat, fish, milk, eggs and vegetables), and accessory foods' (fats, oils, herbs, spices, drinks and fruits). Where staple foods are often unfamiliar in the host country, immigrants tend to consume more of the complementary foods and accessory foods as a method of adaptation.

The concept of adaptation was critically felt by one of the interviewees who moved from Kuwait in search of employment opportunities. Adil started a job involving slaughtering animals, in a way that he was not accustomed to, which forced him to change his attitude towards meat consumption:

I went ahead to do some halal slaughter work as it paid better. Rather than working in the supermarket or McDonald's. I worked as a Muslim, was helping making halal meat as well. So I went ahead with this job for the money, but to be honest, it's not a nice job. Because you see blood everywhere all the time, and from the beginning, I never slaughtered an animal when I lived in Kuwait ... Not entirely, but we used to see sheep being slaughtered, it was done by someone else for Eid celebration to commemorate the end of the fasting month of Ramadan. So I never had an issue with it. However, it was not dealt with daily like I did in halal slaughter places here in NZ. Blood ends up everywhere, you see the internal organs of the animals, and that's not pleasant ... Now I only eat meat when I'm with my family. (Adil, 51, male, Kuwaiti, 3 March 2020) 
Adil's experience with animal slaughter in New Zealand made him change his views around his meat consumption, and he began eating meat mostly only when around family members and not usually at other times. A study conducted by Herzog and McGee (1983) on the reactions of college students to killing and butchering cattle and hogs found that the general attitude towards slaughter was ambivalence. Although most of the students did not enjoy slaughtering and were often upset by it, some students who were more experienced admitted that they felt a sense of accomplishment from this aspect of their work. The less experienced were more likely to say that they sometimes avoided eating meat after slaughtering (Herzog and McGee, 1983).

\subsubsection{Relationships driver}

The present study demonstrates a correlation between one's surroundings and the attitude one has concerning meat and dairy consumption. Of the 13 interviewees, eight were found to be greatly influenced by family and close friends.

I think it's around two or three years now that I have been influenced by friends around me also. I have a lot of vegan and dedicated vegan friends. So when your friends are around you, you prefer to eat vegetarian or vegan and follow their habits. So that's when you hear more about these things and that has influenced me. Meanwhile, in terms of dairy products, I think that it's just not good for me. Therefore, I gave it up more than 10 years ago, especially milk. (Zak, 44, male, Hungarian, 10 February 2020)

This finding strongly supports two elements of Abrahamse's (2019) theory of planned behaviour, and at the general level, supports the entire concept. The two elements are the subjective form-namely, an individual's perception about a particular action, which is influenced by the judgment of significant others (including one's close friends and family 
members ) - and the behavioural intention, which is 'an indication of an individual's interest to perform a given behaviour'. It is assumed to be an immediate antecedent of behaviour. It is based on attitudes toward the behaviour, subjective norm, and perceived behavioural control, with each predictor weighted for its importance relative to the behaviour, and population of interest (Abrahamse, 2019).

Specifically, this means one may not be willing to have a confident attitude towards, say, not eating meat; however, to fit in with the established mindset of those one regards as worth trusting, the individual accepts the option given. For example, Warren described his experience around how he wanted to change his meat and dairy consumption attitudes, but his girlfriend had a negative response to the idea. Here is how he expressed it:

No, she wasn't [keen on the idea]. Which is, of course, not an excuse for me to change my actions or anything, but it stands out in my mind for me, when I'm thinking about [it], I didn't push her into the same thing, as well. I'd never expect that. But I wanted to share it with her one night. And it was definitely where she was like .... Not extreme about it, but [she said] to be in a relationship with you would be very, very hard for me. (Warren, 24, male, Māori, 21 February 2020)

This response illustrates that when Warren attempted to share his feelings concerning his desire to change his attitude towards meat and dairy consumption, his girlfriend responded by indirectly noting the prospect of separation, potentially (and actually) limiting the interviewee from progressing his idea. A study conducted by Ryden and Sydner (2011) on implementing and sustaining dietary change in the context of social relationships found that social relationships were the main barrier to sustaining such change. Therefore, understanding the complexity of accomplishing a healthy dietary change consists of considering the social context in which the changer is involved. Moreover, the changer should be provided with strategies to ease the troublesome situations that might be encountered (Ryden and Sydner, 
2011). This leads to the consideration of the implications of my study in terms of behavioural change.

\subsection{How ethics and values define one's identity}

As demonstrated in Chapter 4, three important crossovers (connections) were identified between the four initial drivers discussed with the participants. These crossovers were:

1. Health-based values and environmental ethics

2. Faith-based values and environmental ethics

3. Faith-based values and animal welfare

I chose to focus on the crossovers that occurred between the value- and ethics-based drivers that defined the participants' behaviour around meat and dairy consumption. The crossovers displayed by the participants show the complex nature of one's attitudes around meat and dairy consumption. I chose the crossovers that paired a value-based attitude with an ethics-based attitude to illustrate the importance of values and ethics in shaping a person's attitude. Research by Zur et al. (2014) explored individuals' motivations for limiting meat and dairy consumption and found that reduction intentions were determined by attitudes, moral beliefs and health beliefs.

Some of the interviewees displayed different concerns regarding their meat and dairy consumption attitudes. For example, Simon expressed his attitudes as strongly environmental and being an avid follower of Buddhism encouraged him to refrain from consuming meat and dairy. This gave him the potential motivation to contribute to environmental mitigation through abstinence from meat and dairy consumption. Zur et al. (2014) expressed that meat consumption reduction is motivated by a broad array of motivations, including morality and health. 
Anwar offered a different perspective, explaining the importance to him of consuming meat to keep the animal population down to prevent overpopulation. However, his statement shows a clear type of misinformation. Thornton (2010) stated that the livestock sector is evolving in response to the rapidly increasing demand for livestock products, especially in developing countries. The domestication of animals has led to the growth of animal agriculture to ensure food production. However, the demand for livestock products in the future could be heavily moderated by socioeconomic factors such as human health and changing socio-cultural values (Thornton, 2010). Different regions around the world will have to deal with the outcome of livestock overpopulation differently. Another study by Castillo (2018) stated that the livestock sector is obliged to adapt to new challenges, depending on the part of the world. It added that climate change is not a matter for developing or developed countries alone; it affects the whole planet (Castillo, 2018). Proper educational campaigns are necessary to educate people to eliminate misinformation and encourage pro-environmental change.

The interviews I conducted for this research show clearly the changes in the attitudes of the participants around their meat and dairy consumption. Consequently, the theory of planned behaviour helps to address misunderstandings around issues like livestock production. Ultimately, it is fortunate that the awareness around people's perception of meat and dairy consumption and environmental degradation is generally increasing. 


\subsection{Mitigation of environmental implications through consumption attitudes}

\section{change}

The effects of meat and dairy consumption on the environment are substantial. During the interviews, those interviewees who had researched the issue identified some of their findings on the pollution caused by the meat and dairy industries and how it can be controlled:

I do work on freshwater quality. So the impacts of animal agriculture on freshwater and on climate. That was based around my interest in freshwater, but that's where it started. So then I started working on freshwater, then I quickly found that the biggest impact on freshwater in New Zealand is animal agriculture, and then I started getting deeper into it and then realised that the animal agriculture is dependent on nitrate fertiliser. And nitrate fertiliser comes from oil. And so, we're actually eating oil, we think we're eating meat, but we're actually eating oil because we couldn't have that density of animals if it wasn't for the subsidy coming from fossil fuel-derived fertiliser, and that goes for the whole planet. We have the population, something like 70 to 80 per cent of the proteins and people, the planet, come from fossil fuel fertiliser-fossil fuel-derived fertiliser. So its implications are in population growth as well. (Mark, 60, male, Pākehā, 3 February 2020)

One significant way in which the meat and dairy industries have curbed the effect of being exposed, is removing the end consumer from understanding the scope and implications of consuming meat and dairy. Further, waste products from the meat and dairy industry often find their way into water systems, polluting them. As discussed in the previous section of this chapter, the theory of planned behaviour is effective in further informing consumers on the impact that meat and dairy consumption has on the environment. For example, a key pollutant of the environment is carbon emissions from the meat industry, which is increasing parallel to meat consumption demands, thus leading to the expansion of those industries. A great 
opportunity is therefore available for mitigating environmental pollution by considering the type of food consumed. With limited meat and dairy consumption, the industrial-scale production would slow down, minimising the release of carbon emissions into the atmosphere. Furthermore, if meat and dairy consumption is limited, the amount of plastic used to wrap the meat and containers used to package milk are also reduced, minimising the pollution caused by the plastic materials used.

Mitigation opportunities come through changes in consumption behaviour, and researching people's values and ethics contributes to developing methods of encouragement to behavioural change. Abrahamse (2019) stated that there is relatively little research on how to encourage people to eat sustainable diets - in particular, research exploring initiatives to encourage people to reduce meat consumption (Dagevos and Voordouw, 2013). The current motivations the participants displayed to reduce their meat and dairy consumption stem from animal welfare, environmental ethics and health-based issues with little reference to faith-based issues.

More research is essential to identify the gaps in people's understanding towards their attitudes around meat and dairy consumption, especially gaps in the understanding of those with faith-based attitudes, as most religious scriptures encourage the consumption of meat and dairy, but also advocate for the protection of the environment and animals. However, religious scriptures tend to be 'cherry-picked' to fit cultural standards, and to meet the demands for meat and dairy consumption. Most people whose faith-based attitudes are secular tend to reduce or eliminate their meat and dairy consumption for ethical reasons. Therefore, it is important to continue to research people's values and ethics around their meat and dairy consumption in order to establish proper educational campaigns that can further inform them about the issues related to meat and dairy today. 
Undertaking this research, and especially writing this discussion chapter made me reflect on my own personal attitudes around meat and dairy consumption. The drivers researched have shaped my attitudes up until today and helped me see the impact of informing the people around me about the importance of increasing our awareness around the issues related to meat and dairy consumption. The amount of passion Aotearoa New Zealand has for its environmental protection is admirable. As someone who came from the desert, I saw and felt the changes in my environment throughout the 28 years of my life. This inspired me to pursue my studies in the attitudes that define our meat and dairy consumption and how addressing them could help mitigate their negative impact on the environment.

\subsection{Research strengths and weaknesses}

All research possesses strengths and suffers from some weaknesses. The limitations of this thesis were as follows:

- Increasing the number of interviewees could expose me to different amounts of opinions and information that would help in developing my findings. I felt the urge to conduct more interviews (around 20 interviews), however, the limits of research time did not provide the ability to conduct more interviews.

- Some participants had trouble expressing their views fully (e.g., Warren had worries about the validity of his opinions).

- Inability to gather information from people associated with other religious backgrounds, which is related to the size of my interview group.

- Selection of participants was semi-random and thus could not expose me to people of different faiths (e.g., Jewish or Hindu). Although I had spoken to most of my participants prior to them agreeing to do the interviews, I could not guarantee that every participant will have a different attitude. (e.g., as seen in Chapter 4, both Mark 
and Paige both defined their attitudes as health-based values and environmental ethics. Omar and Adil both consumed halal meats for faith-based and cultural values).

Below is a list of the strengths of this research:

- Using a qualitative research method helped in gaining the desired information from the context of the data. The main reason for choosing a qualitative research method was due to my own personal abilities to have a one-on-one conversation with individuals on topics of interest. Qualitative research is empirical research where the data are not in the form of numbers (Punch, 1998, p. 4). It involves a naturalistic approach $_{12}$ to the subject matter. My research is about people's behaviour around meat and dairy consumption. Using a quantitative research method is not ideal for obtaining accurate information related to behaviours or contributing to research on the theory of planned behaviour.

- The literature review placed a strong emphasis on why the four selected drivers play a significant role in defining meat and dairy consumer behaviour, which helped in realising that it was best to have a more in-depth look at four groups of people that associate with the drivers.

- The amount of data provided by each participant was significant in understanding people's motivations and how they could contribute to enhancing the effectiveness of encouraging behavioural change. Having a small number of interviewees was an advantage because it prioritised depth over broad coverage.

- The study further confirms Abrahamse's (2019) research findings of individuals who consume meat and dairy for cultural, relational and religious reasons. The sample 
presented in the results shows that although the participants identified with environmental ethics and the importance of protecting the environment, some of them were unaware of the carbon footprint of their food choices. (e.g., Anwar's idea that meat consumption must continue to happen to avoid animal overpopulation on Earth). This is why Abrahamse's (2019) suggestion to enhance education campaigns would be vital to encouraging behavioural change.

- My research was designed to obtain results that can address people's perceptions and increase public awareness of the environmental impact of meat and dairy consumption, which this research has shed light on purposely.

\subsection{Limitations and further research}

Further research may consolidate the present findings of this research and indicate ways of limiting the effects of meat and dairy on human life, the environment and animals.

The method of delivery is critical to encourage behavioural change. Schwartz's (1977) value theory emphasised the importance of understanding the drivers of human behaviour. As stated in Chapter 2, values can be centrally located within a person's belief system; therefore, it is closely related to the self. According to Abrahamse (2019), the reduction of meat consumption could be framed in terms of people's self-transcendence values, emphasising the climate impacts of eating meat, so the message aligns with what is important to people.

This research collected data from a small sample in New Zealand. As discussed in the previous chapter, expanding on the number of participants can give a better range of responses, hence understanding how to encourage behavioural change targeting people's values and ethics around their meat and dairy consumption habits. A larger sample that was more representative of the general population in New Zealand would have a much more diverse input and findings that could help in establishing the best behavioural change approach derived from the theory of 
planned behaviour. That New Zealand is a diverse society is apparent. As seen in Chapter 4, there was a wide variety of attitudes identified by the participants concerning their meat and dairy consumption drivers.

Although ethical principles were set to establish a rigorous study, some limitations were inevitable during data collection and had to be dealt with in real time. This included confidentiality concerns, which resulted in issues with participants in giving personal information such as age and career information. The element of confidentiality took a wide range of variations in that it differs from person to person. One perceives personal information to be confidential while another feels personal information such as health and family information is fine to share with someone.

There is a need for further research from selected ethnic groups, as most of the information collected was from scattered cultural and religious backgrounds. For instance, six participants were not from New Zealand, which, while offering a unique perspective on food choices in this country, limited the information obtained on how the local culture in New Zealand informed meat and dairy consumption. Obtaining the opinions of more Māori would also be helpful. Another way of increasing the sample size would be through a complementary quantitative study.

Further, there was no time to visit the industries that produce meat and dairy to obtain their views regarding the research questions. This should be included in a future study as it would provide information from a producer's perspective. 


\subsection{Discussion Summary}

The discussion chapter began with analysing and presenting the four main drivers with which the participants identified regarding their meat and dairy consumption attitudes. Those drivers were separated into two categories: 1) domain-specific value attitudes 2) ethics-based attitudes. As a result, the drivers displayed the diversity and complexity of peoples' attitudes, ranging from a personal connection to detachment from meat and dairy consumption. Some of the interviewees had other emerging drivers (e.g., cultural drivers and relationships drivers) that defined their meat and dairy consumption attitudes.

The chapter demonstrated how values and ethics intertwine and shape a person's attitude, which is very important in understanding the emphasis of those drivers on meat and dairy consumption today. It shows how important it is to contribute to educational campaigns that encourage behavioural change for the sake of the environment. 


\section{Chapter 6: Conclusion-Where to from here?}

\section{Toitū te marae a Tāne-Mahuta, Toitū te marae a Tangaroa,}

\section{Toitū te tangata.13}

Māori whakataukī (proverb)

The above Māori proverb shows the importance of the land and the sea for people. If the environment suffers, we suffer as well. My final chapter is dedicated to reflecting on my research, starting with addressing my research questions and refining key findings and discussions. Then, it will discuss the limitations and present areas for future research. I conclude with my own reflection on the whole thesis and why I decided to embark on this journey.

My research questions were centred on properly choosing the value- and ethics-based drivers people have around their meat and dairy consumption attitudes, their perceptions of the environmental implications of meat and dairy consumption, and how findings from the research inform behavioural change.

The chosen drivers were carefully selected to fit the requirements and limitations of this research, while covering as much scope as possible in addressing the environmental issues associated with meat and dairy in the literature review of this research. Thirteen participants were interviewed in face-to-face semi-structured interviews. The findings of the interview analysis showed that people's drivers around their meat and dairy consumption are more complex than the originally chosen drivers. It has been observed that significant life events in the participants' lives played a role in shaping and changing their attitudes around meat and dairy consumption.

13 Translation: If the land is well and the sea is well, the people will thrive. 


\subsection{Issues bigger than our attitudes}

It is known that food defines who we are, shapes our everyday lives and has a very personal connection to our individuality. Niki Harré (2018), the author of Psychology for a Better World, described three different levels of action in which an individual can act upon about the environmental dilemma we are currently facing. The personal level is the lifestyle commitment one person can undertake, which includes waste reduction, energy efficiency, buying fair-trade products or, important for this thesis, the food we eat. Harré (2018) described the importance of these personal level practices to inform politicians and businesses that people are ready for these practices.

This research aimed to understand the drivers that define people's meat and dairy consumption attitudes. People's views on their meat and dairy consumption differ based on their reasoning and approach. However, having a clear perception of food's impact on the environment is likely to increase their personal environmental protection efforts. A clear understanding of the relationship between food selection choices and awareness of its environmental impact can therefore be expected to promote sustainability and sound environmental management. The proposed framework presented in Figure 1.1 was designed to see the direction to which behavioural change around meat and dairy consumption could potentially lead.

Protecting the environment includes the protection of all species. The human population continues to grow, and food production is likely to grow as well to meet demand. Therefore, it is crucial to establish a better understanding of why it is essential to shift our current food habits - habits that have shown to be destructive to our environment, health and non-human species in the world. Gaining knowledge of the ethics and values of our food choices will aid in making better environmental management decisions, empowering people to make sustainable food choices to create a better environment. 
As an individual who comes from the UAE, I was exposed to different values and ethics due to the diverse nature of the country. Seeing the different types of food choices available made me embark on this educational journey in Aotearoa New Zealand after 10 years of changing my own personal perception and drivers around my meat and dairy consumption attitudes, realising the importance of changing my lifestyle commitments on a personal level to strengthen my sustainable choices. My educational journey has taught me to have an open mind on the importance of understanding the impact we have on the environment as individuals, and how essential it is to spread this knowledge to the people in our circle to make environmental protection efforts worthwhile.

Aotearoa New Zealand sounded like the best place for me to learn about their extensive efforts to protect and preserve the environment in comparison to my birthplace. Although the UAE is putting in place great initiatives to preserve the environment and improve air quality, the availability of sustainable food choices and encouragement of behavioural change is almost non-existent. Hence why I felt that I have an obligation to study and learn about methods of behavioural change through analysing people's value- and ethics-based drivers around their meat and dairy consumption in Aotearoa New Zealand. 


\section{References}

Abrahamse, W. (2019). Encouraging pro-environmental behaviour: What works, what doesn't, and why. London, United Kingdom: Academic Press.

Ajzen, I. (1988). Attitudes, personality and behavior. Buckingham, England: Open University Press.

Alam, K. F. (1993). Ethics in New Zealand organisations. Journal of Business Ethics, 12(6), $433-440$.

Allen, M. W., Wilson, M., Ng, S. H., \& Dunne, M. (2000). Values and beliefs of vegetarians and omnivores. The Journal of Social Psychology, 140(4), 405-422. doi:10.1080/00224540009600481

Azam, A. (2016). An empirical study on non-Muslim's packaged halal food manufacturers: Saudi Arabian consumers' purchase intention. Journal of Islamic Marketing, 7(4), $441-460$.

Baldini, C., Bava, L., Zucali, M., \& Guarino, M. (2018). Milk production life cycle assessment: A comparison between estimated and measured emission inventory for manure handling. Science of The Total Environment, 625, 209-219.

doi:10.1016/j.scitotenv.2017.12.261

Barriball, K., \& While, A. (1994). Collecting data using a semi-structured interview: A discussion paper. Journal of Advanced Nursing, 19(2), 328-335. doi:10.1111/j.13652648.1994.tb01088.x

Bechtel, R. B. (2010). Environmental psychology. In I. B. Weiner \& W. E. Craighead (Eds.), The Corsini Encyclopedia of Psychology. Hoboken, NJ: John Wiley \& Sons, Inc. doi:10.1002/9780470479216.corpsy03111-3 
Beed, C., \& Beed, C. (1998). Peter Singer's interpretation of Christian Biblical environmental ethics. Worldviews: Global Religions, Culture, and Ecology, 2(1), 53-68. doi:10.1163/156853598X00055

Benningstad, N., \& Kunst, J. (2020). Dissociating meat from its animal origins: A systematic literature review. Appetite, 147, 104554. doi: 10.1016/j.appet.2019.104554

Berger, P. L., \& Luckmann, T. (1966) The social construction of reality: A treatise in the sociology of knowledge. Garden City, NY: Doubleday.

Carroccio, A., Montalto, G., Cavera, G., \& Notarbatolo, A. (1998). Lactose intolerance and self-reported milk intolerance: Relationship with lactose maldigestion and nutrient intake. Journal of the American College of Nutrition, 17(6), 631-636. doi:10.1080/07315724.1998.10718813

Castillo, C. (2018). New challenges of livestock to climate change and overpopulation. Modern Concepts \& Developments in Agronomy, 1 . doi:10.31031/MCDA.2018.01.000521.

Chan, K. M., Balvanera, P., Benessaiah, K., Chapman, M., Díaz, S., Gómez-Baggethun, E., \& Luck, G. W. (2016). Opinion: Why protect nature? Rethinking values and the environment. Proceedings of the National Academy of Sciences of the United States of America, 113(6), 1462-1465.

Chippendale, P. (2001). On values, ethics, morals and principles: A values inventory. Minessence Group.

Chmielewski, C. (2004). The importance of values and culture in ethical decision making. Retrieved 20th of August 2020 from NACADA Clearinghouse of Academic Advising Resources Web site: http://www.nacada.ksu.edu/Resources/Clearinghouse/ViewArticles/Values-and-culture-in-ethical-decision-making.aspx 
Chuvieco, E., Burgui, M., \& Gallego-Álvarez, I. (2016). Impacts of religious beliefs on environmental indicators: Is Christianity more aggressive than other religions? Worldviews: Global Religions, Culture, and Ecology, 20(3), 251-271.

Clonan, A., Roberts, K. E., \& Holdsworth, M. (2016). Socioeconomic and demographic drivers of red and processed meat consumption: Implications for health and environmental sustainability. Proceedings of the Nutrition Society, 75(3), 367-373. doi:10.1017/S0029665116000100

Crocker, J., \& Wolfe, C. T. (2001). Contingencies of self-worth. Psychological Review, 108, 593-623.

Daft, R. L., \& Weick, K. E. (1984) Toward a model of organizations as interpretation systems. Academy of Management Review, 9, 284-295.

Dagevos, H., \& Voordouw, J. (2013). Sustainability and meat consumption: Is reduction realistic? Sustainability: Science, Practice and Policy, 9(2), 60-69. doi:10.1080/15487733.2013.11908115

de Boer, J., Schösler, H., \& Boersema, J. (2013). Climate change and meat eating: An inconvenient couple? Journal of Environmental Psychology, 33(C), 1-8. doi:10.1016/j.jenvp.2012.09.001

Deckers, J. (2010). Should the consumption of farmed animal products be restricted, and if so, by how much? Food Policy, 35(6), 497-503.

Diaz, S., Settele, J., Brondízio, E., Ngo, H., Guèze, M., \& Agard, J. (2020). Summary for policymakers of the global assessment report on biodiversity and ecosystem services of the Intergovernmental Science-Policy Platform on Biodiversity and Ecosystem Services (Research Report). Retrieved from University of the West England Research Repository Website: https://uwe-repository.worktribe.com/output/1493508/summaryfor-policymakers-of-the-global-assessment-report-on-biodiversity-and-ecosystem- 
services-of-the-intergovernmental-science-policy-platform-on-biodiversity-andecosystem-services

Dowd, K., \& Burke, K. J. (2013). The influence of ethical values and food choice motivations on intentions to purchase sustainably sourced foods. Appetite, 69, 137-144.

Drew, J., Cleghorn, C., Macmillan, A., \& Mizdrak, A. (2020). Healthy and climate-friendly eating patterns in the New Zealand context. Environmental Health Perspectives, $128(1), 017007$.

Drew, J. M. (2018). Healthy \& climate-friendly eating patterns for New Zealand. Unpublished doctoral dissertation. University of Otago, New Zealand.

Eccles, J. S., \& Harold, R. D. (1991). Gender differences in sport involvement: Applying the Eccles' expectancy-value model. Journal of Applied Sport Psychology, 3, 7-35.

Eccles, J. S., \& Wigfield, A. (1995). In the mind of the actor: The structure of adolescents' academic achievement related-beliefs and self-perceptions. Personality and Social Psychology Bulletin, 21, 215-225.

Eimers, Y., Pieters, R., Verhallen, T., Antonides, G., \& van Raaij, W. (1994). Product evaluation as a function of consumer type and usage situation. Tilburg School of Economics and Management. Integrating Views on Economic Behavior, 32-50.

Elferink, E., Nonhebel, S., \& Moll, H. (2008). Feeding livestock food residue and the consequences for the environmental impact of meat. Journal of Cleaner Production, 16(12), 1227-1233. doi:10.1016/j.jclepro.2007.06.008

Environment Aotearoa 2019. (2019). Ministry for the Environment \& Stats NZ. Retrieved from: https://www.mfe.govt.nz/publications/environmental-reporting/environmentaotearoa-2019 
Ferguson, L. R. (2002). Meat consumption, cancer risk and population groups within New Zealand. Mutation Research/Fundamental and Molecular Mechanisms of Mutagenesis, 506, 215-224.

Ferguson, L. R. (2010). Meat and cancer. Meat science, 84(2), 308-313.

Fiala, N. (2008). Meeting the demand: An estimation of potential future greenhouse gas emissions from meat production. Ecological Economics, 67(3), 412-419.

Flyvbjerg, B. (2001). Making social science matter: Why social inquiry fails and how it can succeed again. Cambridge, UK: Cambridge University Press.

Foote, K., \& Joy, M. (2014, August). The true cost of milk: Environmental deterioration vs. profit in the New Zealand dairy industry. Paper presented at the New Zealand Agricultural and Resource Economics Society 2014 Conference, Nelson, New Zealand. Retrieved from http://ageconsearch.umn.edu/record/187496/

Friel, S., Dangour, A. D., Garnett, T., Lock, K., Chalabi, Z., Roberts, I., ... \& Haines, A. (2009). Public health benefits of strategies to reduce greenhouse-gas emissions: food and agriculture. The Lancet, 374(9706), 2016-2025.

Fuccillo, A., Sorvillo, F., \& Decimo, L. (2016). Law, religions and food choices. CALUMET - Intercultural Law and Humanities Review. Retrieved from http://www.windogem.it/calumet/archivio_single.asp?id_art=49\&lang=eng

GMI (2020). United Arab Emirates Population Statistics. Retrieved 16 August 2020, from https://www.globalmediainsight.com/blog/uae-population-statistics/

Godfray, H., Garnett, T., \& Godfray, H. (2014). Food security and sustainable intensification. Philosophical Transactions of the Royal Society of London. Series B, Biological Sciences, 369(1639), 20120273-20120273.

https://doi.org/10.1098/rstb.2012.0273 
Goldstein, D. (2013). Eating and ethics in Shakespeare's England. Cambridge University Press. London.

Grossi, G., Goglio, P., Vitali, A., \& Williams, A. (2019). Livestock and climate change: Impact of livestock on climate and mitigation strategies, Animal Frontiers, 9(1), 6976, doi:10.1093/af/vfy034

Harré, N. (2018). Psychology for a better world: Working with people to save the planet. Auckland: Auckland University Press.

Herzog, H. A., Jr \& McGee, S. (1983) Psychological aspects of slaughter reactions of college students to killing and butchering cattle and hogs, International Journal for the Study of Animal Problems, 4, 124-132.

Holmboe-Ottesen, G., \& Wandel, M. (2012). Changes in dietary habits after migration and consequences for health: A focus on South Asians in Europe. Food \& Nutrition Research, 56(1), 1-13. doi:10.3402/fnr.v56i0.18891

Honkanen, P., \& Olsen, S. O. (2009). Environmental and animal welfare issues in food choice. British Food Journal, 111(3), 293-309. doi:10.1108/00070700910941480

Hope, A., \& Jones, C. (2014). The impact of religious faith on attitudes to environmental issues and Carbon Capture and Storage (CCS) technologies: A mixed methods study. Technology in Society, 38(C), 48-59. doi:10.1016/j.techsoc.2014.02.003

Ho-Pham, L., Nguyen, P., Le, T., Doan, T., Tran, N., \& Nguyen, T. (2009). Veganism, bone mineral density, and body composition: A study on Buddhist nuns. Osteoporosis International, 20(12), 2087-2093. https://doi.org/10.1007/s00198-009-0916-Z

Hughes, J. (2012). SAGE Internet research methods. In SAGE Internet Research Methods. SAGE Publications. London Ltd. doi:10.4135/9781446268513

Hughey, K. F.D., Kerr, G.N., \& Cullen, R. (2016). Public perceptions of New Zealand's environment: 2016. Christchurch: EOS Ecology. 
Irwin, A. (2001). Devoured by God: Cannibalism, mysticism, and ethics in Simone Weil. CrossCurrents, 51(2), 257-272.

Jerry J. Vaske, M. (1999). A value-attitude-behavior model predicting wildland preservation votingiIntentions. Society \& Natural Resources, 12(6), 523-537. https://doi.org/10.1080/089419299279425

Jones, R., Wham, C., \& Burlingame, B. (2019). New Zealand's food system is unsustainable: A survey of the divergent attitudes of agriculture, environment, and health sector professionals towards eating guidelines. Frontiers in Nutrition, 6, 99. https://doi.org/10.3389/fnut.2019.00099

Kagan, S. (1992). The structure of normative ethics. Philosophical Perspectives, 6, 223-242. https://doi.org/10.2307/2214246

Karwowski, M., \& Barbot, B. (2016). Creative self-beliefs: Their nature, development, and correlates. In Creativity and Reason in Cognitive Development (pp. 302-326).

Kass, L. R. (1999). The hungry soul: Eating and the perfecting of our nature. Chicago: University of Chicago Press.

Cambridge University Press. https://doi.org/10.1017/CBO9781139941969.016

Kopnina, H., Washington, H., Taylor, B., \& Piccolo, J. J. (2018). Anthropocentrism: More than just a misunderstood problem. Journal of Agricultural and Environmental Ethics, 31(1), 109-127.

Kroese, F. M., Marchiori, D. R., \& de Ridder, D. T. (2015). Nudging healthy food choices: A field experiment at the train station. Journal of Public Health, 38(2), e133-e137.

Lamine, C. (2015). Sustainability and resilience in agri-food systems: Reconnecting agriculture, food and the environment. Sociologia ruralis, 55(1), 41-61 
Lever, J., \& Fischer, J. (2019). Similarities and differences between kosher and halal. In Kosher and Halal Business Compliance (1st ed., pp. 14-15). Routledge. https://doi.org/10.4324/9781315159874-3

Lindeman, M., \& Väänänen, M. (2000). Measurement of ethical food choice motives. Appetite, 34(1), 55-59.

Lloyd, K. (2012). New Zealand government oversight of halal certification of animal products exported from New Zealand. Auckland University Asia Dialogue July 2012.

McIntyre, L., \& Dutton, M. (2015). Eating and activity guidelines for New Zealand adults. Ministry of Health. Retrieved from: https://www.health.govt.nz/publication/eatingand-activity-guidelines-new-zealand-adults

McMichael, A. J. (2013). Globalization, climate change, and human health. New England Journal of Medicine, 368(14), 1335-1343.

Miller, J., \& Glassner, B. (2011) The 'inside' and the 'outside': Finding realities in interviews, qualitative research (3rd edition). SAGE Publications. London.

Mobayed, T., Abdullah, A., Abuleil, A., El-Zaher, S., El-Zaher, S., \& El-Zaher, S. et al. (2016). How halal is the 'halal' meat industry? Mvslim. Retrieved 18 July 2020 from https://mvslim.com/halal-halal-meat-industry/

Mohamed, Z. (2011). The complementary effect of halal principles and sustainable concept. David Publishing Company.

Morris, S. T. (2013). Sheep and beef cattle production systems. In Dymond JR (Ed.)

Ecosystem Services in New Zealand. Lincoln, New Zealand: Manaaki Whenua Press. Myung-Bae, P., \& Chun-Bae, K. (2020). Influence of alcohol and red meat consumption on life expectancy: Results of 164 countries from 1992 to 2013. Nutrients, 12(2). doi:10.3390/nu12020459

Ogden, J. (2003). The psychology of eating. Carlton, Victoria: Blackwell Publishing Ltd. 
Oppedijk van Veen, W., \& Verhallen, T. (1986). Vacation market segmentation: A domainspecific value approach. Annals of Tourism Research, 13(1), 37-58. https://doi.org/10.1016/0160-7383(86)90056-3

Perignon, M., Vieux, F., Soler, L. G., Masset, G., \& Darmon, N. (2017). Improving diet sustainability through evolution of food choices: Review of epidemiological studies on the environmental impact of diets. Nutrition Reviews, 75(1), 2-17.

Pilgrim, F. J. (1957). The components of food acceptance and their measurement, American Journal of Clinical Nutrition, 5, 171-175.

Popkin, B. M. (2009). Reducing meat consumption has multiple benefits for the world's health. Archives of Internal Medicine, 169(6), 543. doi:10.1001/archinternmed.2009.2

Prescott, J., Young, O., O’Neill, L., Yau, N. J. N., \& Stevens, R. (2002). Motives for food choice: A comparison of consumers from Japan, Taiwan, Malaysia and New Zealand. Food Quality and Preference, 13(7-8), 489-495.

Punch, K. (1998). Introduction to social research: Quantitative \& qualitative approaches. (1st ed.) SAGE. London.

Radnitz, C., Beezhold, B., \& DiMatteo, J. (2015). Investigation of lifestyle choices of individuals following a vegan diet for health and ethical reasons. Appetite, 90, 31-36.

Raelin, J. (2007). Toward an epistemology of practice. Academy of Management Learning \& Education, 6(4), 495-519. doi:10.5465/AMLE.2007.27694950

Ripple, W. J., Smith, P., Haberl, H., Montzka, S. A., McAlpine, C., \& Boucher, D. H. (2014). Ruminants, climate change and climate policy. Nature Climate Change, 4(1), 2-5.

Ritchie, H., \& Roser, M. (2017). Meat and dairy production. Our World in Data. Retrieved 7 October 2019 from https://ourworldindata.org/meat-production\#meat-productionacross-the-world. 
Roe, R. A., Schwartz, S. H., \& Surkiss, S. (1999). Basic individual values, work values, and meaning of work. Applied Psychology: An International Review, 48, 49-71.

Rokeach, M. (1973). The nature of human values. New York: Free Press.

Rowlands, M. (2013). Animal rights: All that matters. John Murray Press. London.

Rozenberg, S., Body, J. J., Bruyère, O., Bergmann, P., Brandi, M. L., Cooper, C., ...

Reginster, J. Y. (2016). Effects of dairy products consumption on health: Benefits and beliefs-A commentary from the Belgian Bone Club and the European Society for Clinical and Economic Aspects of Osteoporosis, Osteoarthritis and Musculoskeletal Diseases. Calcified tissue international, 98(1), 1-17. https://doi.org/10.1007/s00223015-0062-x

Rydén, P., \& Sydner, Y. (2011). Implementing and sustaining dietary change in the context of social relationships. Scandinavian Journal of Caring Sciences, 25(3), 583-590. doi:10.1111/j.1471-6712.2010.00867.x

Sanchez-Sabate, R., \& Sabate, J. (2019). Consumer attitudes towards environmental concerns of meat consumption: A systematic review. International Journal of Environmental Research and Public Health, 16(7), 1220. doi:10.3390/ijerph16071220

Schwartz, S. (1977). Normative influences on altruism. Advances in Experimental Social Psychology, 221-279. doi:10.1016/s0065-2601(08)60358-5

Schwartz, S. H. (1992). Universals in the content and structure of values: Theory and empirical tests in 20 countries. In M. Zanna (Ed.), Advances in experimental social psychology (Vol. 25, pp. 1-65). New York: Academic Press. doi:10.1016/S00652601(08)60281-6

Schwartz, S. (2012). An overview of the Schwartz Theory of basic values. Online Readings in Psychology and Culture. 2. 10.9707/2307-0919.1116 
Seves, S., Verkaik-Kloosterman, J., Biesbroek, S., \& Temme, E. (2017). Are more environmentally sustainable diets with less meat and dairy nutritionally adequate? Public Health Nutrition, 20(11), 2050-2062. doi:10.1017/S1368980017000763

Silverman, D. (2011). Qualitative Research (3rd ed.). SAGE Publications. London Singer, P. (2005). Eating ethically. Free Inquiry, 25(4), 18-19. Retrieved from ProQuest Database: http://search.proquest.com/docview/230126995/

Singer, P. (2011). Practical ethics (3rd ed.) Cambridge: Cambridge University Press. Springmann, M., Wiebe, K., Mason-D’Croz, D., Sulser, T., Rayner, M., \& Scarborough, P. (2018). Health and nutritional aspects of sustainable diet strategies and their association with environmental impacts: A global modelling analysis with countrylevel detail. The Lancet Planetary Health, 2(10), e451-e461. doi:10.1016/S2542$5196(18) 30206-7$

Stenmark, M. (2017). Environmental ethics and policy-making. Routledge. London. https://doi.org/10.4324/9781315256320

Swagerty, D. L. Jr, Walling, A. D. \& Klein, R. M. (2002). Lactose intolerance. American Family Physician, 65(9), 1845-1850.

Thornton, P. K. (2010). Livestock production: Recent trends, future prospects. Philosophical transactions of the Royal Society of London, Series B, Biological sciences, 365(1554), 2853-2867. doi:10.1098/rstb.2010.0134

Tucker, C. (2018). Using environmental imperatives to reduce meat consumption: Perspectives from New Zealand. Kōtuitui: New Zealand Journal of Social Sciences Online, 13(1), 99-110, doi:10.1080/1177083X.2018.1452763

United Nations, Department of Economic and Social Affairs, Population Division (2019). World Population Prospects 2019: Highlights. ST/ESA/SER.A/423. 
Verplanken, B., \& Holland, R. (2002). Motivated decision making: Effects of activation and self-centrality of values on choices and behavior. Journal of Personality and Social Psychology, 82. 434-47. 10.1037/0022-3514.82.3.434.

Vinson, D., Scott, J., \& Lamont, L. (1977). The role of personal values in marketing and consumer behavior. Journal of Marketing, 41(2), 44-50. doi:10.2307/1250633

Vogel, T., \& Wanke, M. (2016). Attitudes and attitude change. Psychology Press. Routledge. London.

Watkins, L., Aitken, R., Hinder, C., Lawson, R., Mather, D., Paul, A., ... Robertson, K., \& Williams, J. (2015). The New Zealand consumer lifestyle segments. New Zealand Sociology, 30(1), 111-130.

Westhoek, H., Lesschen, J., Rood, T., Wagner, S., De Marco, A., Murphy-Bokern, D., ... Oenema, O. (2014). Food choices, health and environment: Effects of cutting Europe's meat and dairy intake. Global Environmental Change, 26(C), 196-205. https://doi.org/10.1016/j.gloenvcha.2014.02.004

Willett, W., Rockström, J., Loken, B., Springmann, M., Lang, T., Vermeulen, S., ... Murray, C. J. L. (2019). Food in the Anthropocene: the EAT-Lancet Commission on healthy diets from sustainable food systems. The Lancet, 393(10170), 447-492. doi:10.1016/S0140-6736(18)31788-4

Wilson, N., Nghiem, N., Mhurchu, C. N., Eyles, H., Baker, M. G., \& Blakely, T. (2013). Foods and dietary patterns that are healthy, low-cost, and environmentally sustainable: A case study of optimization modeling for New Zealand. PloS One, 8(3).

Wines, W., \& Napier, N. (1992). Toward an understanding of cross-cultural ethics: A tentative model. Journal of Business Ethics, 11(11), 831-841. Retrieved August 26, 2020, from http://www.jstor.org/stable/25072344 
World Wildlife Fund (2017). Appetite for Destruction. Retrieved from:

https://www.wwf.org.uk/sites/default/files/201710/WWF_AppetiteForDestruction_Summary_Report_SignOff.pdf

Yinger, J. (1967). Pluralism, religion, and secularism. Journal for the Scientific Study of Religion, 6(1), 17-28. https://doi.org/10.2307/1384190

Zur, I., \& Klöckner, C. (2014). Individual motivations for limiting meat consumption. British Food Journal, 116. 629-642. 10.1108/BFJ-08-2012-0193. 


\section{Appendices}

\section{Appendix A: Information sheet for participants}

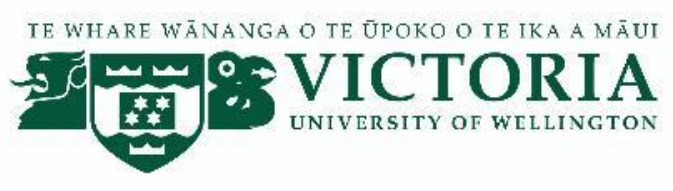

\section{People's Values and Ethics around Meat and Dairy Consumption in New Zealand}

\section{INFORMATION SHEET FOR PARTICIPANTS}

You are invited to take part in this research. Please read this information before deciding whether or not to take part. If you decide to participate, thank you. If you decide not to participate, thank you for considering this request.

\section{Who am I?}

My name is Mariam Alzaabi and I am a Master's student in Environmental Studies at Victoria University of Wellington. This research project is work towards my thesis.

What is the aim of the project?

This project is aimed to study the values and ethics-based attitudes behind meat and dairy consumption in New Zealand and its relationship to environmental implications. Your participation will support this research by understanding the reasons why people choose to consume or not meat and dairy products in New Zealand. This research has been approved by the Victoria University of Wellington Human Ethics Committee 0000028121. 


\section{How can you help?}

You have been invited to participate because you associate your meat and dairy consumption/ refrainment with a value or ethic-based reasoning such as health, religion or animal welfare. If you agree to take part, I will interview you in a public library or café in Wellington CBD that is convenient for both of us. I will ask you questions about meat and dairy consumption. The interview will take between 45 and 90 minutes. I will audio record the interview with your permission and write it up later. You can choose to not answer any question or stop the interview at any time, without giving a reason. You can withdraw from the study by contacting me at any time before 25 March 2020. If you withdraw, the information you provided will be destroyed or returned to you.

\section{What will happen to the information you give?}

This research is confidential. This means that the researcher named below will be aware of your identity but the research data will be combined and your identity will not be revealed in any reports, presentations, or public documentation.

Only my supervisors Marcela Palomino-Schalscha and Paul Blaschke and I will read the notes or transcript of the interview. The interview transcripts, summaries and any recordings will be kept securely and destroyed on $31^{\text {st }}$ of July 2023.

\section{What will the project produce?}

The information from my research will be used in my Master's thesis research an academic publications and conferences.

\section{If you accept this invitation, what are your rights as a research participant?}

You do not have to accept this invitation if you don't want to. If you do decide to participate, you have the right to:

- $\quad$ choose not to answer any question;

- $\quad$ ask for the recorder to be turned off at any time during the interview; 
- $\quad$ withdraw from the study before 25 March 2020;

- $\quad$ ask any questions about the study at any time;

- $\quad$ receive a copy of your interview recording;

- $\quad$ receive a copy of your interview transcript;

- $\quad$ read over and comment a copy of your interview;

- be able to read any reports of this research by emailing the researcher to request a copy.

If you have any questions or problems, who can you contact?

If you have any questions, either now or in the future, please feel free to contact either:

\section{Student}

Name: Mariam Fahed Alzaabi

University email address:

alzaabmari@myvuw.ac.nz

\section{Supervisor:}

Name: Marcela Palomino-Schalscha

Role: Lecturer

School: School of Geography, Environment and Earth Sciences

Phone: 044635899

marcela.palomino-schalscha@vuw.ac.nz

\section{Human Ethics Committee information}

If you have any concerns about the ethical conduct of the research you may contact the Victoria University HEC Convenor: Dr Judith Loveridge. Email hec@vuw.ac.nz or telephone +64-4-463 6028. 


\section{Appendix B: Consent to interview}

TE WHARE W̄ ĀNANGA O TE L̈POKO O TE IKA A MĀUI

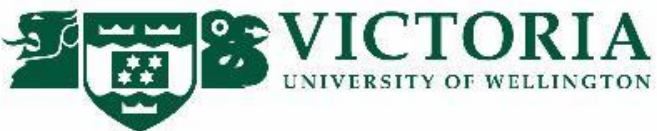

\section{People's Values and Ethics Around Meat and Dairy Consumption in New Zealand}

\section{CONSENT TO INTERVIEW}

This consent form will be held for 3 years.

Researcher: Mariam Alzaabi, SGEES, Victoria University of Wellington.

- I have read the Information Sheet and the project has been explained to me. My questions have been answered to my satisfaction. I understand that I can ask further questions at any time.

- I agree to take part in an audio recorded interview.

I understand that:

- I may withdraw from this study at any point before $31^{\text {st }}$ July 2023 , and any information that I have provided will be returned to me or destroyed.

- $\quad$ The identifiable information I have provided will be destroyed on $31^{\text {st }}$ of July 2023. 
- $\quad$ Any information I provide will be kept confidential to the researcher and the supervisor Marcela Palomino-Schalscha.

- I understand that the findings may be used for a Master's degree and an academic publication and conferences.

- I understand that the recordings will be kept confidential to the researcher and Mariam's supervisors.

- $\quad$ My name will not be used in reports and utmost care will be taken not to disclose any information that would identify me.

- I would like a copy of the recording of my interview:

Yes $\square \quad$ No $\square$

- I would like a copy of the transcript of my interview:

Yes $\square \quad$ No $\square$

- I would like a summary of my interview:

Yes $\square \quad$ No $\square$

- I would like to receive a copy of the final report and have added my email Yes No $\square$ address below.

Signature of participant:

Name of participant:

Date:

Contact details: 


\section{Appendix C: Questions list for participants}

\section{General questions/warm up questions:}

- Age:

- Occupation:

- Ethnicity:

- Do you consume meat and/or dairy?

- What are the reasons behind your preference around your consumption of meat and dairy?

- Can you give me key reasons why you choose to consume or not consume meat and dairy products? (preferably 3 key reasons)

- Would you say these reasons are connected to:

- Religion

- Health

- Environmental concerns

- Animal welfare

- Other? Explain

\section{Domain-specific value attitudes around meat and dairy consumption key questions}

- Faith-based views:

- Tell me how does your religion perceive the environment, in your interpretation? (Or what is the value of the environment in (your religion)?) 
- Based on (your religion), what is the role of people with regards to the environment and other creatures?

- Based on (your religion), how do you individually see your values behind meat and dairy consumption?

- In your view, how does your religion deal with current environmental issues related to meat and dairy consumption?

- How does your religion influence your personal choice to consume or not consume meat and dairy products? Are there any points of tensions?

- (question about animal slaughter in the name of religion)

\section{- Health-based views:}

- What is your perception of the relationship between meat and dairy consumption and human health? (personally, and for human health generally)

- Why have you decided to consume or not consume meat and/or dairy products?

- How has your view of the relationship between meat and dairy consumption and human health influenced this decision?

○ Do you think there are some benefits of meat and/or dairy consumption?

- How is your meat and dairy consumption influenced by other drivers in your lifestyle or values?

\section{Ethical-based attitudes arounds meat and dairy consumption questions}

\section{- Environmental ethics:}

- Tell me about your understanding of the relationship between environmental values and meat and dairy consumption?

- Why have you decided to consume or not consume meat and/or dairy products? 
- How does your understanding of environmental concerns influence your choice to consume or not consume meat and dairy products? Why?

- How can environmental ethicists in New Zealand address the current environmental issues related to dairy and meat consumption?

\section{- Animal welfare:}

- How do you perceive the relationship between meat and dairy consumption to animal welfare?

- Why have you decided to refrain from or consume meat and/or dairy consumption?

- Why do you base your meat and dairy consumption on animal welfare grounds? What does it mean for you?

- How can ethicists in New Zealand address the current issues related to dairy and meat consumption, especially around the animal welfare aspects? (may need to provide a little background to this question) 


\section{Appendix D: Email to participants}

Dear [Participant]

My name is Mariam Alzaabi and I am a master's student at Victoria University of Wellington, pursing my master's in environmental studies.

I am looking for participants who are willing to be interviewed for the purpose of collecting data for my thesis research.

My thesis research title: People's Values and Ethics around Meat and Dairy Consumption in New Zealand

My thesis in a nutshell:

In New Zealand, 1 out of 3 people choose to rethink their consumption of animal products, particularly meat. My research aims to gather qualitative information on attitudes related to meat and dairy consumption that revolves around faith, health, environmental ethics and animal welfare. These four attitudes have stood out the most when it comes to analysing people's values and ethics around the consumption/non-consumption of meat and dairy consumption.

The aim of this interview is to have an in-depth look behind one of the four attitudes that you find yourself associated with, to find their relationship with the current food consumption patterns known today and their environmental impact.

If you are interested in participating, we both will agree on a place that is comfortable to conduct the interview such a café, and I will accommodate to your availability. The interview will take between 45 and 60 minutes.

I am happy to provide any additional information and answer any questions you might have.

Looking forward to hearing back from you,

Mariam 